\title{
La coordinación de las Administraciones Públicas
}

\author{
Luis Fajardo Spínola
}

\begin{abstract}
SUMARIO: I. INTRODUCCION. II. COORDINACION Y AUTONOMIA. III. COORDINACION DE LAS CORPORACIONES LOCALES CON OTRAS ADMINISTRACIONES. 1. Relaciones interadministrativas. 2. La Coordinación en la Ley de Régimen local. 2.1. Coordinación a través de la Cooperación. 2.1.1. Coordinación y Cooperación. 2.1.2. Modalidades de la Cooperación. 2.1.3. Instrumentos y procedimientos para la Cooperación. 2.1.4. Organización para la Cooperación. 2.2. Coordinación forzosa. Condicionamiento de la actividad de las Corporaciones locales al servicio de una acción pública coordinada. IV. COORDINACION ENTRE COMUNIDADES AUTONOMAS Y ESTADO. 1. Generalidades. 2. Cooperación para la Coordinación. 2.1. Modalidades e instrumentos. Los convenios 2.2. Organización para la Coordinación. 3. Coordinación forzosa. V. HACIA UN MODELO INTEGRADO DE COORDINACION. 1. Introducción. 2. Coordinación de la actividad de las Corporaciones locales con la de otras Administraciones: un modelo integrado. 2.1. Un sistema integrado de coordinación sectorial. 2.2. El Plan sectorial de cooperación. 3. Coordinación de Comunidades Autónomas y Estado: un modelo integrado.
\end{abstract}

\section{INTRODUCCION}

Constante aspiración de todos los reformadores y de todos los administradores ha sido siempre la de alcanzar la mayor coordinación de las diferentes actuaciones públicas que persiguen un mismo resultado. El logro de tal objetivo se torna especialmente difícil cuando - como en el caso español- nos encontramos ante un sistema complejo, con varios centros autónomos de iniciativa político-administrativa desplegando acciones dirigidas al mismo fin. Consolidado un alto nivel de autonomía política para las diversas Administraciones que integran nuestro Estado, se hace más necesario que nunca contar con mecanismos que favorezcan la convergencia y la unidad. A este empeño responde el presente trabajo, que trata de estudiar la coordinación de la actividad de las diferentes Administraciones Públicas ${ }^{1}$.

\footnotetext{
1 «...donde está el nervio de hierro verdadero de la actuación de las partes del Estado compuesto suele ser siempre en la Administración, pues es ahí donde la superioridad del sistema descentralizado puede manifestarse fácilmente. Es en este terreno, sobre todo, donde nuestro sistema autonómico tiene también que ganar su partida..." E. GARCIA DE ENTERRIA, prólogo a A. Jiménez Blanco, "Las relaciones de funcionamiento entre el poder central y los entes territoriales", Madrid 1985, pág. 20.
} 
Ya en los Acuerdos Autonómicos de 1981, las fuerzas políticas parlamentarias que los suscribieron reflejaban la conveniencia de regular legalmente un sistema para la coordinación de las funciones propias de las Diputaciones Provinciales por parte de las Comunidades Autónomas, así como la armonización de la actividad de éstas con la del Estado. Con escasas modificaciones, su contenido sería asumido por la LOAPA y en parte conservado por el Tribunal Constitucional 2. Estamos todavía, sin embargo, ante un sistema muy limitado y aún poco perfeccionado, que para las Diputaciones acudía a una fórmula de neotutela, que no se refería a la coordinación de las demás Corporaciones locales, y que para lo relativo a las relaciones Estado-Comunidades Autónomas prácticamente se limitaba a proponer como técnica coordinadora la de las Conferencias Sectoriales (así como las fórmulas de relación y coordinación que ambas partes libremente convinieran a través de los Decretos de Transferencias: art.19 LPA).

La sentencia del Tribunal Constitucional relativa a la LOAPA reconoce la necesidad (y constitucionalidad) de «la creación de instrumentos que permitan articular la actuación de las diferentes Administraciones Públicas" 3; sin embargo, a partir de entonces el principio de coordinación cae en esa zona maldita de las cuestiones altamente polémicas en la relación Estado-Comunidades Autónomas, y tal vez por ello durante mucho tiempo no se ha abordado su aplicación efectiva a través de un sistema integrado que concitará el acuerdo de todos. Unicamente se abordaría la cuestión en lo relativo a las Corporaciones Locales, a lo largo del proceso de preparación y elaboración de la nueva ley de Régimen Local, cuyo resultado final es bien conocido de todos y aquí

\footnotetext{
2 La coordinación de las Diputaciones se realizaría por Ley de la Asamblea Autonómica aprobada por mayoría absoluta, y en la cual se establecerían las fórmulas generales de coordinación y la lista de funciones provinciales coordinables (Acuerdos Autonómicos, 1981, I, 5.1); se proponía, pues, establecer un sistema de coordinación forzosa, dudosamente compatible con la autonomía provincial constitucionalmente amparada. El posterior proyecto de LOAPA no incorporaría este supuesto, que tampoco aparece a lo largo de su elaboración parlamentaria, ni en el texto finalmente aprobado. En cuanto a la coordinación entre Comunidades Autónomas y Estado, el anteproyecto de LOAPA incorporado a los referidos Acuerdos regula ya la figura de las Conferencias Sectoriales, para "asegurar la imprescindible coordinación"; el artículo en cuestión (el 9 del Anteproyecto) fue finalmente mantenido en el texto de la LOAPA, si bien suscitó recelos y reticencias a lo largo del debate parlamentario de la parte de algún grupo nacionalista (Congreso de los Diputados, sesión plenaria del día 23 de junio de 1982, Diario de Sesiones n. ${ }^{\circ} 252$, pág. 14.666).

3 STC de 5 de agosto de 1983, FJ 13. En este mismo FJ se considera por ello ajustado a la Constitución el establecimiento de Conferencias Sectoriales, cuyos acuerdos serán en principio no obligatorios para las partes, salvo cuando se trate de materias en las que la Constitución atribuye al Estado la facultad de coordinar.
} 
estudiaremos en particular. Tal vez sea ahora cuando por fin se está a punto de entrar en una nueva fase, caracterizada por el diseño y aplicación concordados de sistemas integrados de coordinación, basados en una común cultura de la cooperación entre Administraciones 4 .

A lo largo de todo este período la doctrina se ocupó de la coordinación, aportando materiales muy interesantes para la elaboración de una teoría general de la misma a partir de nuestra Constitución, de los Estatutos de Autonomía y de la legislación de desarrollo ${ }^{5}$. A través de

\footnotetext{
${ }^{4}$ En los primeros borradores de LRL las técnicas de coordinación de Diputaciones, y de otras Corporaciones además cuando hubiere fallado la fase cooperativa (art. 55), eran mucho más duras para la autonomía local que las que finalmente recogió el Proyecto de Ley; fue la intervención del Grupo Parlamentario Socialista, dentro de la habitual fase de propuestas de modificación previas, la que proporcionó los textos finalmente incorporados, para hacer compatible la coordinación forzosa con la autonomía local mediante la técnica ya regulada en el vigente artículo $59 \mathrm{LRL}$. A este episodio seguramente se refiere L. PAREJO ALFONSO cuando afirma, en "Relaciones interadministrativas y régimen local», REDA 40/41, que "existe (en el proyecto de Ley) un cierto desfallecimiento del sistema respecto de sus propuestas de partida, que trae causa de las razones ya expuestas más atrás, reconducibles al mundo de las opciones políticas" (pág. 222). La nueva Ley de Régimen Jurídico de las Administraciones Públicas y del Procedimiento Administrativo Común (Ley 30/1992, de 26 de noviembre), recoge el principio de la coordinación de competencias; contempla la coordinación intersubjetiva (entre órganos de diferentes Administraciones) y la intrasubjetiva (entre los órganos de la misma Administración). En todo caso, se asegura en tal artículo el respeto a la competencia de cada uno de los coordinados, y de su texto se desprende que la coordinación es un deber de los agentes administrativos pero que no puede imponerse desde fuera.
}

5 M. PALLARES MORENO, "La coordinación de la Administración periférica en España», Madrid 1969 (estudia especialmente la CPST); E. LINDE PANIAGUA, «La coordinación de las Administraciones públicas en la Constitución de 1978», Madrid 1981 (especial referencia a la función coordinadora de los Delegados del Gobierno); J.M. CASTELL ARTECHE, "El ámbito relacional de las Corporaciones locales», Rev, Vasca de Adm. pública, 1/81, págs. 35 s.s.; M. ALVAREZ RICO, "El principio de coordinación en el Estado de las Autonomías", Doc. Adm., 1982, n. ${ }^{\circ} 196$, págs. 5 s.s.; S. MUÑOZ MACHADO, «Derecho público de las Comunidades Autónomas», Madrid 1982, t.I, págs. 218 s.s.; V.M. ESCUIN PALOP, «Análisis de las soluciones italianas a los problemas del regionalismo cooperativo", Doc. Adm., abril-junio 1983, págs. 29 s.s.; J.M. BOQUERA OLIVER, "Comunidades autónomas y Administraciones locales", REVL, n. ${ }^{\circ}$ 219, 1983, pág. 424; L. PAREJO ALFONSO, "Estado social y Administración pública», Madrid 19883; P. SANTOLAYA MACHETTI, «Descentralización y cooperación», Madrid 1984, págs. 33 s.s. y 289 s.s.; A. JMENEZ BLANCO, "Las relaciones de funcionamiento entre el poder central y los entes territoriales", Madrid 1985, págs. 255 a 322; R. MARTIN MATEO, "Manual de Derecho autonómico", $2^{a}$ edic., Madrid 1986, págs. 284 a 289; L PAREJO ALFONSO, "La autonomía local», REALA, n. ${ }^{\circ} 229$, 1986; Jurisprudencia Comentada ("coordinación», Sent. 3-686), RAP 113, pág. 258; LOPEZ RAMON, «Planificación territorial», RAP 114, 1987, págs. 127 s.s.; ORTEGA ALVAREZ, "Principios constitucionales sobre régimen local», RAP 117. 1988, págs. 172 a 176 y 187 a 189; E. ARGULLOL, «La coordinación entre las Comunidades Autónomas y las entidades locales», Comunidades Autónomas y gobiernos locales, Barcelona 1987, págs. 163 a 179; vid. en esta misma obra colectiva que se acaba de 
las líneas que siguen queremos aportar nuestra contribución a un tema tan crucial en el funcionamiento del Estado de las Autonomías.

\section{COORDINACION Y AUTONOMIA}

El modelo que la Constitución y los Estatutos establecen responde claramente al principio de la autonomía de las partes o componentes del sistema estatal, reconociendo como es bien sabido ámbitos diferenciados de ejercicio de poder político-administrativo en los niveles nacional, autonómico y local. Unos sistemas de distribución de competencias, determinados y concretados en sucesivos momentos, formalizan jurídicamente el alcance y límites de aquel poder y legitiman a las distintas Administraciones para su ejercicio. Pero con la misma claridad y contundencia con que se formula en nuestros textos políticos fundamentales el principio de autonomía, se explicita y proclama el de unidad. Los agentes públicos autónomos forman un conjunto dotado de identidad y personalidad política propia, y con vocación de responder globalmente - sin detrimento de su pluralismo interno- a las demandas de la comunidad nacional. La Constitución de 1978 ha puesto en pie una original fórmula institucional que combina equilibrada y armónicamente dos principios, aparentemente antagónicos, los de autonomía y unidad; y para alcanzar esta delicada conjunción, el propio texto constitucional y todo el sistema jurídico-público que lo desarrolla, establecen un complejo y rico esquema de relaciones interadministrativas, que constituye sin duda una de las claves de su funcionamiento.

Pocas referencias constitucionales y estatutarias se dedican a la coordinación entre la Administración del Estado y las de las Comunidades Autónomas. En cuanto a las relaciones interadministrativas en que la Administración local es parte, la Constitución se limita a reconocer indirectamente la existencia de unas relaciones Administración del Estado-Corporaciones locales en las que aquélla ostentaría ciertas funciones respecto de éstas, al tiempo que autoriza las transferencias de tales funciones a las Comunidades Autónomas a través de la legislación estatal de Régimen local (art. $148 \mathrm{CE}$ ).

citar, artículos sobre coordinación interadministrativa de R. MIRO, F. PURAS, J. DOMENECH, C. CALLEJA, L.F. VELASCO, EX. ESTEVEZ, A. CHOY, E. MORRAS, L. AMARGOS, y M. FDEZ. CORONADO. Vid. también de doctrina extranjera, M. PALOTTINO, "Strumenti giuridici di concertazione amministrativa: l'accordo di programma», Riv. Amm. 134, dic. 1983, págs. 847 ss.; G. ROLLA, «L'attivitá di indirizzo e coordinamento ed i suoi limiti», Le Regioni, XI/6, 1983, p. 1190 ss.; F. PIGA, «L'attivitá di ccordinamento", Il Foro Amm. LXIII, 1987, págs. 1302 ss. 
Los Estatutos de Autonomía son más explícitos que la Constitución en la regulación del tema, pero casi exclusivamente se limitan a establecer facultades comunitarias de coordinación sobre las Corporaciones locales de su territorio y particularmente sobre las Diputaciones, todo ello en el marco de la legislación estatal de Régimen local.

El Tribunal Constitucional, por su parte, ha iniciado una interesante línea de tratamiento jurisprudencial de la cuestión de las relaciones entre las diversas partes o componentes del Estado, tendentes a la consecución del principio de unidad:

- Así, la Sentencia del Tribunal Constitucional de 4 de mayo de 1982 reconoce la existencia de «un deber de colaboración dimanante del general deber de auxilio recíproco entre unidades estatales y autonómicas..., (deber que) se encuentra implícito en la propia esencia de la forma de organización territorial del Estado».

- Esta colaboración resulta deseable también en relación con las autoridades municipales (STC. 8 de junio de 1982).

- Y en idéntica línea se mantienen las Sentencias de 4 de noviembre de 1982, 28 de abril de 1983 y la de 5 de agosto de 1983 (LOAPA).

En resumen, del análisis del conjunto del bloque de constitucionalidad en relación con esta materia se deduce que estas relaciones en las que la Administración local está llamada a participar son elementos determinantes del modelo de organización territorial del Estado, que deben tender -con respeto de la autonomía de cada parte- a la consecución del principio de unidad, y que su regulación básica se encomienda a la legislación estatal de régimen local. Como más adelante veremos, otra línea jurisprudencial reconoce la posibilidad -además- de coordinación por la del Estado de la Administración de las Comunidades Autónomas, en aquellos supuestos previstos por la Carta fundamental.

Finalmente, antes de pasar al estudio de las relaciones interadministrativas en nuestro Derecho, conviene un breve repaso del tratamiento de la materia en dos de los ordenamientos jurídicos extranjeros más próximos: Italia y la República Federal de Alemania.

En la Ley italiana número 142, de 8 de junio de 1990, que establece el nuevo ordenamiento de las autonomías locales, se dedica un número importante de artículos a la regulación de las relaciones interadministrativas. El sistema, muy similar al de nuestra Ley de Régimen Local, responde al principio de la libre cooperación y se basa en planes sectoriales a diferentes niveles. Se facilita la coordinación entre tales niveles (regional, 
provincial y municipal) a través de una técnica programatoria en la que la provincia desempeña un especial papel mediador, y donde el plan de desarrollo regional establece principios y objetivos generales (art. 3) a los cuales deberá adecuarse tanto el Plan territorial de coordinación como los programas plurianuales (ambos provinciales: art. 15). Entre los instrumentos al servicio de la cooperación deben distinguirse los establecidos para desarrollar de modo coordinado funciones y servicios determinados («convenzioni»: art. 24), de aquéllos de carácter transitorio convenidos para hacer frente a la ejecución en común de una concreta obra o intervención públicas (acuerdos de programa: art. 27).

En un Estado federal como el alemán el sistema de relaciones interadministrativas se encuentra muy desarrollado, a partir de una rica experiencia de funcionamiento, que incluso propició nada menos que toda una reforma constitucional. El sistema, sin embargo, se encuentra principalmente elaborado para el tratamiento de las relaciones entre el Bund y los Länder, si bien su filosofía general también se proyecta sobre el esquema relacional de éstos con los Municipios. El modelo de federalismo cooperativo alemán incluye muchas técnicas y modalidades no formalizadas; pero aparte de ellas, la Constitución federal expresamente desarrolla tres sistemas principales de cooperación: el de las tareas comunes obligatorias, el de las tareas comunes facultativas y el de las ayudas financieras a la inversión. Declaradas comunes determinadas tareas por Ley federal, los Länder formulan propuestas para la elaboración del Plan-Marco donde se van a contener las actuaciones coordinadas; el Plan Marco sería elaborado por una comisión mixta Gobierno Federal-Gobierno de los Estados, donde un complicado sistema de mayoría asegura un amplio apoyo político para la inclusión de concretos proyectos; los respectivos ejecutivos quedan obligatoriamente vinculados a consignar en sus presupuestos las cantidades para financiar tales proyectos y ejecutarlos luego. En el sistema de tareas comunes facultativas no se impone la cooperación como en el anterior, sino que se fomenta y facilita por diversos medios, principalmente de orden financiero. Mediante el sistema de ayudas federales a la inversión, finalmente, se consigue vincular la actividad de los Länder a ciertas áreas o sectores de especial interés para el Bund, si bien no puede éste llegar a condicionar la inclusión de concretos proyectos en los programas regionales de inversión pública.

\section{COORDINACION DE LAS CORPORACIONES LOCALES CON OTRAS ADMINISTRACIONES}

\section{Relaciones interadministrativas}

El sistema de relaciones interadministrativas que diseña la Ley de Régimen local española se inscribe en la línea de autonomismo 
cooperativo que hemos visto recogida en nuestro propio ordenamiento constitucional, y que encontramos también en las experiencias más próximas del Derecho comparado.

Para hacer real el mandato constitucional -art. 103 - de una actuación eficaz y coordinada 6, las Administraciones del Estado y de las Comunidades Autónomas, por un lado, y las Administraciones locales por el otro, deberán ajustar sus recíprocas relaciones a una serie de pautas o reglas legalmente definidas (art. 55 LRBRL).

A. Deben ajustar su actuación al reconocimiento y respeto de las competencias de las demás Administraciones (art. 55 a) LRBRL); el Estado y las Comunidades Autónomas vendrán obligados a autolimitar el ejercicio de su propia competencia en atención a la existencia de unas competencias legalmente definidas, y las entidades locales adoptarán a su vez idéntica actitud en consideración de las facultades y poderes estatales o comunitarios. Nuestro sistema relacional, pues, se basa en el esquema - previo- del reparto de competencias a cada nivel de Gobierno (nacional, regional y local), reparto de competencias propias a cada Administración que dota de contenido a su respectiva autonomía. Las relaciones a las que la Ley de Régimen local se refiere son, pues, relaciones entre entes autónomos, entre sujetos dotados de iniciativa para la formulación de sus propias políticas y para la defensa de los intereses que les atañen; de ahí precisamente que nunca puedan llegar a establecerse relaciones de subordinación entre ellos, de ahí también que incluso en los supuestos extremos de coordinación forzosa nunca pueda llegarse a la usurpación de la competencia, al vaciamiento del poder legalmente asignado. Y es por eso, justamente, por lo que el artículo 10.3 LRBRL palmariamente proclama que «las funciones de coordinación no afectarán en ningún caso a la autonomía de las entidades locales».

Este respeto por el ámbito de poder de los demás no se limita al reconocimiento de la competencia ajena formalmente adjudicada; sino que también se debe extender a la consideración de los intereses en juego en cada caso, cuando la gestión de los mismos viene encomendada a otras Administraciones.

Nos encontramos aquí ante la proclamación de un principio de lealtad mutua en el ejercicio de las propias competencias.

\footnotetext{
6 Para ALVAREZ RICO, op. cit., pág 22, «la aplicación de los principios de organización contenidos en el artículo 103.1 a todas las Administraciones públicas sólo puede defenderse de forma indirecta"; sin embargo, en base al 149.1.18, corresponde al Estado la fijación -dentro del procedimiento administrativo común - "de una serie de principios comunes a todas las organizaciones públicas, entre las que figura a no dudarlo el principio de coordinación..., como principio rector de las relaciones intersubjetivas...» (pág. 23).
} 
B. Junto a estas limitaciones en el ejercicio de la propia competencia, principalmente dirigidas a evitar la colisión y el enfrentamiento, el sistema de relaciones que comentamos impone - además- algunos deberes positivos a las partes de esa relación, deberes todos ellos que pretenden promover y alcanzar una acción convergente de todos los poderes públicos, una tendencia a la afirmación del principio de unidad estatal al que antes nos referíamos. Estos deberes positivos, formulados por la Ley de Régimen local, son los siguientes:

a) Facilitar información sobre la propia gestión a las demás Administraciones públicas. No hay aquí una obligación de «pasarlo todo", lo que supondría una inútil complicación burocrática, sino sólo aquéllo que resulte relevante para la realización de sus propios cometidos por los entes que van a ser informados. Este deber genérico se concreta, entre otras, en la obligación de las Corporaciones locales de remitir a la Administración del Estado y a la de la Comunidad Autónoma copia (o extracto, cuando por su extensión y características parezca aconsejable) de sus actos y acuerdos; resulta claro deducir que esta información sirve de base a la iniciativa de control de legalidad de los actos administrativos locales. Las corporaciones locales no disfrutan de la correspondiente información sobre las disposiciones y actos estatales o comunitarios, que les permita acudir a la Jurisdicción en defensa de su autonomía, por lo que habrán de procurársela por los medios habituales de publicidad en lo que se refiere a las disposiciones generales, o a través de la correspondiente notificación en cuanto a los actos o resoluciones que les afecten.

b) Otro deber positivo de las Administraciones públicas incluído en el sistema de sus relaciones es el de prestar ayuda y asistencia activa a las demás entidades para facilitar el cumplimiento de sus tareas. No se trata de una acción conjunta, no se trata de acompañar a la Administración que actúa a lo largo de todo el proceso de su desarrollo y conclusión, sino solamente el responder positivamente a sus requerimientos con intervenciones puntuales accesorias de la principal a su cargo. Constituye ésta una clara manifestación del principio de solidaridad aplicado a las relaciones interadministrativas. Como más adelante se verá, la ayuda y asistencia a otras Corporaciones locales puede y debe - para supuestos determinados- establecerse con carácter permanente, a través de mecanismos y formas organizativas institucionales.

c) Otro deber positivo que la Ley impone (art. 58.2 in fine) es el de permitir a las otras Administraciones la participación en 
los procesos de programación y planificación de la propia actividad. Se trata, pues, de la participación en la programación ajena; y no, de ninguna forma, de alguna modalidad humillante de intervención en la planificación de tareas de las que el participante también sea titular (competencias propias actuadas cooperativamente). Entendemos que para que esta participación resulte efectiva para todos, y no se convierta en un puro requisito formal, deberá concluir:

$\left.a^{\prime}\right)$ La inicial solicitud de información y de sugerencias en relación con la materia que va a ser objeto de programación.

b') La periódica remisión de información, a lo largo de las distintas fases del proceso planificador, acerca de los sucesivos acuerdos y resoluciones que se vayan integrando en el proyecto.

c') La información del anteproyecto de plan inmediatamente antes de su aprobación, solicitando la opinión al respecto.

C. Se impone también la obligación de cooperar preferentemente en colaboración con otras Administraciones. Es sin duda el principal deber implícito en todo nuestro modelo de relaciones interadministrativas. Aunque más que un deber es una invitación permanente del sistema a actuar cooperativamente; es la pendiente inclinada por donde naturalmente discurrirán las Administraciones públicas hacia los comunes objetivos al servicio de los ciudadanos. Al análisis y fijación de posición sobre la cooperación dedicamos las páginas que siguen.

\section{La coordinación en la Ley de Régimen local}

\subsection{Coordinación a través de la cooperación}

\subsubsection{Coordinación y cooperación}

A lo largo de todo el capítulo II del Título V de nuestra Ley municipal se manifiesta con claridad y firmeza la más acendrada fe, la creencia más intensa, en la libre cooperación entre Administraciones públicas. Todo nuestro sistema de relaciones interadministrativas está montado sobre la idea de que el principio de unidad no se alcanza por la imposición de unas entidades sobre las otras, por la vía jerárquica, sino a partir de la libre concurrencia de los diversos agentes públicos autónomos a los fines comunes a todos. Al concepto de cooperación está unido el de libertad y voluntariedad; pero por si cupieran dudas, el art. 57 de 
nuestra LRL claramente lo proclama para cualquier tipo de cooperación. Es por eso por lo que en este cuadro sólo excepcionalmente encajan las fórmulas de condicionamiento externo de la voluntad autónoma de las diversas entidades, y siempre con límites prefijados para evitar precisamente la vejación de su autonomía.

La coordinación es aquel estado de armonía y de coincidencia tanto en los resultados del actuar de diferentes unidades administrativas como en las metas intermedias a lo largo del proceso para alcanzar tales resultados. La coincidencia y la armonía se dan cuando hay identidad de objetivos y de prioridades, sin que sea necesaria esta identidad en cuanto al modo (técnicas, instrumentos, procedimientos, etc.) que cada una de aquellas unidades administrativas aplicó para alcanzarlos. El resultado de una acción coordinada es mérito, a veces, de intervenciones ajenas - y por tanto externas- a los propios entes u órganos coordinados. En otros casos, tales agentes administrativos "se coordinan" entre sí, sin acción externa alguna; es decir, son protagonistas tanto de la acción coordinada como de las acciones para coordinar. Cuando la acción coordinadora es externa a los entes coordinados, quien puede o debe intervenir desde fuera se dice que ostenta facultades de coordinación; tales facultades, sin embargo, no siempre suponen el ejercicio de poderes superiores o jerárquicos, de tal manera que -como enseguida veremos- la coordinación externa de la acción de entes autónomos no tiene por qué significar una limitación insoportable de su autonomía.

La cooperación, en cambio, es aquel modo de actuar administrativo en que dos o más unidades con cometidos diferentes voluntariamente relacionan y vinculan entre sí los respectivos procedimientos con vistas a alcanzar resultados predeterminados. La cooperación es conjunción, encuentro, proceso interactivo; no siempre significa acción conjunta, pues también se coopera cuando el actuar de cada cooperante resulta identificable por separado. La contribución de cada cooperante es igualmente importante y necesaria para el resultado que se espera, y no cabe calificar a una de principal y a otra de accesoria; tal diferencia de rango sí se da entre el que colabora y el que recibe la colaboración. Por eso, casi siempre puede diferenciarse cooperación de colaboración. La cooperación, finalmente, es siempre voluntaria.

Y a su vez la cooperación sirve a una finalidad más amplia: la coordinación. Conviene diferenciar ambos conceptos, el de la cooperación del de la coordinación. La coordinación es el fin, y la cooperación es el medio (o mejor, el modo); y no el único medio, pues la coordinación también puede alcanzarse por otros caminos, incluso por el de la directriz autoritaria o por el de la consigna imperiosa. Pero como más arriba se señaló, ésta no es la forma en que en nuestro sistema jurídico local re- 
sulta lícito alcanzar la coordinación, pues siempre debe tenerse en cuenta el no atentar contra la autonomía local (artículo 10.3 LRBRL).

Algunos autores, empeñados en encontrar diferencias entre coordinación y cooperación, han querido ver en aquélla ciertos elementos jerárquicos, incompatibles con la idea de cooperación o colaboración; nos parece rechazable este tipo de argumentación, pues en ningún caso ni siquiera cuando en nuestro sistema se alcanza la coordinación por medios no cooperativos- pueden reconocerse en las técnicas empleadas actitudes de superioridad jerárquica. Como más adelante veremos, la técnica coordinadora del artículo 59 LRBRL no establece relaciones de jerarquía entre coordinador y coordinado ?.

Nuestro sistema de distribución de competencias -incluso cuando se complete, por la vía de asignación a través de Leyes sectoriales a las Corporaciones locales de las que les corresponda- no establece ni establecerá compartimentos estancos, incomunicables, repletos de competencias propias absolutamente exclusivas, sin concurrencia alguna sobre las de las demás Administraciones. Resulta deseable la mayor precisión posible en relación con este reparto de funciones y tareas entre los distintos agentes públicos; pero sabemos de antemano que muchas serán las zonas comunes, los solapamientos y las convergencias, en el actuar de sus competencias por parte de cada uno de ellos. También por todo eso la cooperación se impone.

Finalmente, queremos señalar que las Corporaciones locales no están llamadas a cooperar solamente en su mismo plano de actividad ordinaria; sino que también atenderán la cooperación descendente (sobre todo la de Diputaciones y Cabildos respecto de otras entidades locales de nivel territorial inferior), y la ascendente $\multimap$ participación cooperativa en la formulación de políticas generales de nivel superior-.

\subsubsection{Modalidades de la cooperación}

La nueva Ley de Régimen local establece diversas modalidades de cooperación, y variados instrumentos y procedimientos para alcanzarla. A

\footnotetext{
7 Vid. SANTOLAYA MACHETTI, op. cit., págs. 33 y 312. Vid. también L. ORTEGA, "La garantía de la autonomía local en el reparto competencial entre las Administraciones públicas", en Comunidades Autónomas y gobiernos locales, cit., págs. 315 a 317. También puede consultarse A. FONTANA I PUIG, "Les relacions interadministratives a la lleu reguladora de les bases de régim local", Rev. Valenciana d'Estudis Autonomics, oct-dic., 1987, págs. 63 a 85. En la línea, en cambio, que defendemos en nuestro texto, vid. A. NIETO GARCIA, "Cooperación y asistencia", en el colectivo "La provincia en el sistema constitucional», Ed. Civitas, Madrid 1991, págs 145 a 165.
} 
su vez, pone en pie un sistema extraordinario dirigido a lograr la coordinación entre Administraciones cuando no se utilizaron, fracasaron o resultaron inadecuadas las técnicas cooperativas. No hay una lista cerrada de modalidades de cooperación; y en cada una de las modalidades pueden introducirse variantes y modificaciones que permitan ajustarse a cada situación a resolver cooperativamente. Así y todo, procede hacer una breve y sumaria relación de algunas de ellas:

\section{A) Acción paralela no contradictoria}

Podemos afirmar que es el grado mínimo de colaboración, cuando llega a serlo. Se trata más bien de una actitud pasiva respecto del conjunto, limitándose a constatar las posiciones de los demás y a proponerse no interferirlas. Esta actitud puede incluso resultar de un acuerdo previo, después de comprobar el riesgo de colisiones competenciales y de convenir así que las Administraciones marchen cada una por su camino aunque evitando el enfrentamiento con las demás ${ }^{8}$.

\section{B) Reparto de tareas}

De un acuerdo entre las Administraciones competentes en una materia puede surgir un reparto de tareas entre ellas, de tal manera que se consiga una complementariedad que beneficie al conjunto.

\section{C) Acción conjunta}

Las entidades públicas convienen asumir conjuntamente la responsabilidad de la acción en un sector, y desarrollarla de la misma forma. No debe confundirse esta figura, cooperativa y por eso libremente convenida, con la que contempla el artículo 62 de la Ley, donde la acción conjunta ha sido impuesta por el legislador al asignar la competencia. Las Administraciones que acuden a esta modalidad de acción conjunta cooperativa normalmente se servirán de algún organismo interpuesto, creado al efecto de común acuerdo ${ }^{9}$.

\footnotetext{
8 Un medio muy válido para ello resulta sin duda la participación en la planificación o programación ajenas: art. 58.2 LRL; art. 19.3 Ley 14/1990 de Administraciones públicas canarias; art. 134 Ley Municipal y de Régimen local de Cataluña, 15-4-87. En una interesante Sent. del T.S. de 3 de junio de 1986 (ponente FCO. GONZALEZ NAVARRO) se expone un muy preciso concepto de coordinación (Fdo. Jur. $3 .^{\circ}$ ) referible a las estructuras jerarquizadas, y que - pienso- no excluye la coordinación voluntaria.

9 Art. 69 del Texto Refundido de Régimen local, RDL 781/86. El art. 136 del citado RDL 3046/1977, precedente del vigente, decía: «Las competencias compartidas o concurrentes
} 


\subsubsection{Instrumentos y procedimientos para la cooperación}

También muchos y variados resultan los instrumentos de los que se dispone para la colaboración entre entes públicos; vamos a referirnos a los más importantes entre los que son utilizados habitualmente por la Administración local:

\section{A) Convenios y acuerdos de cooperación}

Resultará el mecanismo más frecuente para alcanzar la cooperación en una materia, sobre todo cuando no exista un esquema permanente de colaboración al que acogerse (Planes Provinciales, por ejemplo). Como figura contractual que es, su contenido será el que las partes le asignen: pueden existir, sin embargo, convenios de adhesión, de contenido y características prefijados por una Administración, que son suscritos por el ente cooperante sin discutir las condiciones, simplemente adhiriéndose al mismo. Esta última figura resulta válida siempre que la naturaleza de sus cláusulas y condiciones no impongan una auténtica situación dependiente y negadora de su autonomía al cooperante, lo que podría llegar a resultar contrario a nuestro Derecho local.

De cada acuerdo de cooperación - señala el art. 57- formalizado por la Administración local de un lado y la estatal o la autonómica del otro, se dará comunicación a aquella otra que, resultando interesada, no haya intervenido en el mismo, a los efectos de mantener una recíproca y constante información. En el modelo de cooperación que más adelante proponemos, esta función informativa se refuerza con la anotación del convenio suscrito en la relación correspondiente del Plan Sectorial de Coordinación ${ }^{10}$.

\section{B) Planes provinciales de Obras y Servicios}

Figura ya tradicional en nuestro régimen local, sigue constituyendo una magnífica técnica para la cooperación, especialmente para la que

\footnotetext{
podrán ser ejercidas conjuntamente por la Administración del Estado y la local mediante la constitución de entes instrumentales de carácter público o privado..." La legislación autonómica ya ha recogido también la regulación de esta modalidad de cooperación; así, la Ley 14/1990 de Canarias, en su art. 17 prevé la constitución de sociedades mixtas por varias Administraciones para servicios con contenido económico; o mediante consorcios, art. 135 de la Ley de Régimen local de Cataluña de 15 de abril de 1987.

10 La legislación de las Comunidades Autónomas se refiere a esta figura de cooperación: artículos 29 y 30 de la Ley de Consejos Insulares de Baleares de 1939; el art. 15 de la Ley canaria 14/1990; y para los convenios en materia de servicios sociales, los artículos 23 a 25 de la Ley canaria 9/1987, de 28 de abril, o el art. 30.2 de la Ley 5/87 de 23 de abril de la C.A. de Extremadura; entre muchos otros. Con carácter general, vid. LLISET BORRELL, «Los convenios interadministrativos de los entes locales», REDA n. ${ }^{\circ} 67$ 1990, págs. 389 a 400.
} 
pueda surgir entre el primero y el segundo nivel de nuestra Administración local (Diputaciones o Cabildos y Municipios). Modificada recientemente su regulación por RD 665/1990, de 25 de mayo, se han introducido importantes novedades; pero sus líneas básicas se mantienen al servicio de una cooperación en los niveles territoriales inferiores del Estado, donde nos encontramos con las limitaciones financieras y técnicas de los pequeños municipios y con las grandes dificultades debidas al rápido crecimiento de los barrios marginales.

En base a lo dispuesto en el art. 36.2 de la Ley, el Plan que estudiamos seguirá centrado sobre la Diputación/Cabildo, constituyendo la pieza clave de su acción de cooperación. La Diputación a través de sus planes provinciales, podría constituirse en lugar de encuentro sobre el territorio de la acción cooperativa de las distintas Administraciones, cuando se trate de desarrollar obras y servicios de competencia municipal (art. 6.2 RD 665/1990).

El Plan provincial de cooperación a las obras y servicios municipales no es un plan sectorial, no establece previsiones en una única materia; se trata de un plan general territorial, orientado a la cooperación en materias de naturaleza local.

En la elaboración del Plan, dice la Ley, deben participar los municipios de la provincia; esta exigencia podría resultar una redundancia - ya el art. 58.2 in fine concede esa participación en general-, si no fuera porque debe entenderse que la norma pretende asegurar una participación especialmente intensa a las Corporaciones municipales, dada la naturaleza del documento a elaborar 11. Consultas y conversaciones deberá emprender también la Diputación con las Administraciones de otro nivel que pretenden financiar parcialmente el Plan. La Ley autoriza, por cierto, al Estado y a la Comunidad Autónoma, cuando se dé esta cofinanciación, a "sujetar sus subvenciones a determinados criterios y condiciones en su utilización o empleo"; pero este condicionamiento parece más bien referirse al modo de utilizar los fondos, que puede llegar incluso al establecimiento de estándares de eficiencia en el empleo de los mismos (plazos máximos para tener contratados los proyectos, tiempo para la financiación de su ejecución, etc...). Todo ello sin perjuicio de la acomodación de los Planes a los objetivos y prioridades establecidos para la coordinación.

«La Comunidad Autónoma asegura en su territorio la coordinación de los diversos planes provinciales de acuerdo a lo previsto en el artículo

11 Art. 43 d) Ley 14/1990 de las Administraciones públicas canarias: los Cabildos no podrán modificar las propuestas municipales al Plan Insular de Cooperación. 
59 de esta Ley». La aplicación de este párrafo del artículo 36 plantea inicialmente algunas dificultades de interpretación, pues el artículo al cual se remite establece una técnica de coordinación por planes, planes además de naturaleza sectorial. ¿Se pretende considerar la de los planes provinciales como una materia más, que puede ser a su vez objeto de un plan coordinador superior?. Eso parece absurdo; ni la de los planes provinciales, como más arriba quedó aclarado, constituye una materia o sector de la actividad pública directa hacia los ciudadanos, sino instrumental, ni cabe pensar en un Plan de Planes, que complicaría innecesariamente el modelo. Parece suficiente conectar los Planes provinciales - a efectos de su coordinación - con todos aquellos Planes Sectoriales de Coordinación que por razón de las materias en cada caso les afecten. Se consigue una simplificación del sistema general de coordinación, y -además - se alcanza un objetivo de enorme importancia: vincular la planificación general territorial (PPOS) con la sectorializada (PSC).

En resúmen, el sistema de coordinación de Planes Provinciales funcionará de la siguiente forma:

a) No se precisará Ley sectorial previa en cada caso para considerar otorgadas las facultades de coordinación, pues éstas se atribuyen por la propia Ley de Régimen Local.

b) Los PPOS deberán adecuar los proyectos que incluyan a los objetivos y prioridades que hemos convenido en llamar Instrucciones Generales para la coordinación, y que para diferentes sectores de acción pública han sido incluidos en los correspondientes Planes Sectoriales de Coordinación.

c) También aquí debe entenderse que el sistema prefiere alcanzar la coordinación por modos libremente pactados (cooperación voluntaria), si bien se establece la posibilidad de la aplicación del mecanismo ya analizado del artículo 59 de la Ley.

En el Plan provincial (insular) de Cooperación a las obras y servicios municipales la libre concurrencia de las Administraciones se alcanza por sucesivas adhesiones a la inicial propuesta de la Diputación o Cabildo insular. Siendo éstos los competentes para aprobarlo, de acuerdo con su respectivo Plan plurianual de inversiones, los municipios y otras entidades - al solicitar la inclusión de una concreta obra o servicio en el Planformulan también su adhesión al esquema de cooperación provincial. Finalmente, concluido el Plan, se remite al Ministerio de Administraciones públicas, que lo «analizará... a fin de acordar su participación»; es decir, a fin de adherirse o no al mismo (art. 8 RD 665/1990). 
Otra modalidad de la cooperación económica del Estado y las Corporaciones locales es la de los Programas de Acción Especial para ciertas comarcas o zonas deprimidas (artículos 18 a 27 RD 665/1990); o bien la de los programas sectoriales de cooperación (artículos 28 y 29 del citado Real Decreto).

C) Planificación urbanística y coordinación. Ordenación del territorio.

Conviene destacar la íntima relación entre el objetivo general de la coordinación interadministrativa y los documentos de ordenación territorial y urbanística. Algunas Comunidades Autónomas ya han comenzado a legislar en la materia, por lo que se impone la generalización de un criterio por parte de las corporaciones locales al respecto. En todo caso, baste por ahora el dejar sentados al menos tres principios básicos:

a) No solamente no resulta contradictoria la ordenación y planificación territorial con la coordinación interadministrativa sectorializada, sino que ambos bloques de armonización política deben a su vez estar debidamente entrelazados a través de las técnicas y procedimientos que en cada caso resulten más convenientes.

b) La ordenación territorial y el planteamiento urbanístico deben también reflejar los principios de voluntaria coordinación y de libre cooperación que presiden el sistema de las relaciones interadministrativas en general.

c) La ordenación territorial y el planeamiento urbanístico nunca podrán resultar en perjuicio de la autonomía local, ni desconocedores de las competencias en la materia de las entidades locales 12 .

\section{D) ¿Qué planificación regional?}

El modelo de planificación concertada o cooperativa que se regula en la LRL se basa, precisamente, en un conjunto de planes regionales sectoriales a partir de los cuales se monta todo el sistema. Además, y como acabamos de ver, en cada provincia existirá un plan territorial, el de cooperación en las obras y servicios municipales. ¿Debe existir para el territorio de toda la Comunidad Autónoma algún esquema general de previsiones afectando a todos los sectores?.

12 Vid. infra, Cap. IV, 3, in fine, sobre la ordenación territorial. 
La Ley 7/1984, de 31 de marzo, reguladora del Fondo de compensación interterritorial establece, en su artículo 8, que todas las Comunidades Autónomas vendrán obligadas a elaborar un programa de Desarrollo Regional (PDR) de acuerdo con la metodología común que aprobará el Gobierno. Esta metodología se recoge en la Resolución de 25 de marzo de 1985 de la Subsecretaría de Hacienda; por otro lado, como ya hemos señalado, la Ley de Presupuestos Generales del Estado para 1986 (art. 60.3) impuso a las Comunidades Autónomas la obligación de tener aprobado su PDR.

Parece claro que el PDR se va a convertir en el Plan Territorial a nivel de cada Comunidad Autónoma. Su finalidad es la de «lograr actuaciones coherentes de las distintas Administraciones públicas que permitan evitar ineficiencias en la asignación de unos recursos limitados", la de "coordinar e integrar actuaciones que, - para el logro de dichos objetivos (objetivos realizables con el volumen de recursos disponibles)planean emprender los poderes públicos", así como la de conectar con el sistema de ayudas FEDER-CEE.

Se pretende que los PDR incluyan algunas (o todas) las ayudas con finalidad regional y las inversiones en infraestructura decididas y/o programadas por los distintos niveles de gobierno sobre el territorio. No incluirá, pues, solamente proyectos de iniciativa comunitaria, sino también otros cuya responsabilidad corresponde a la Administración del Estado o - sobre todo- a las Administraciones locales; y es por eso por lo que se prevé la financiación a base de aportaciones provenientes de los Presupuestos del Estado, de los de la propia Comunidad Autónoma y de los de las Corporaciones locales. Parece fuera de toda duda que el PDR incluirá, pues, previsiones y decisiones de varias Administraciones públicas; ahora bien, ¿previsiones y decisiones distintas de todas aquellas incluidas en Planes Sectoriales de coordinación o en Planes provinciales de obras y servicios? Pensamos que no, que el PDR debe incluir precisamente aquella parte de tales planes parciales que suponga una aportación al desarrollo regional. De ahí que el proceso de elaboración del PDR, al que debe resultarle de aplicación cuanto hemos dicho sobre la participación de otros en el proceso planificador propio, vaya a convertirse en la fase final y la consecuencia de todo el sistema de planificación concertada o cooperativa que se ha descrito 13 .

13 Vid. infra los comentarios que dedicamos a los PDR con ocasión de la coordinación forzosa del Estado sobre las Comunidades Autónomas en materia de planificación general de la economía (art. 149.1.13 CE), en el Cap. IV, 3 del presente estudio. 


\subsubsection{Organización para la cooperación}

Tampoco aquí cabe pensar en una lista cerrada de organismos para la cooperación, por lo que vamos a referirnos a los más importantes; distinguiremos, en primer lugar, los permanentes o generales, de los transitorios o sectoriales; y en segundo lugar - por la extensión de su influencia- los de ámbito autonómico de los de ámbito provincial. Por la forma o modo de funcionamiento, unos serán exclusivamente deliberantes o consultivos (a los que el artículo 58 denomina órganos de colaboración), mientras que otros pueden asumir cometidos de gestión de actividades y servicios cooperativamente (consorcios o sociedades mercantiles mixtas: artículos 85 y 87 de la Ley).

De entre los distintos organismos permanentes o generales que pueden existir para la colaboración con las Corporaciones locales, la Ley destaca dos figuras a las que dedica algunos párrafos: las Comisiones Territoriales de Administración local y la Comisión Nacional de Administración local.

A través de la Comisión Nacional de Administración local, las provincias y los municipios españoles deberán tender a participar activamente en la preparación y formulación de las grandes opciones de política general, alimentando estos procesos con su información local de primera mano y en defensa siempre de una actuación descentralizada y participativa de los poderes públicos.

En cuanto a las Comisiones Territoriales de Administración local, su finalidad es la de asegurar la colaboración entre la Administración del Estado y la local, en materia de inversiones y prestación de servicios, en el ámbito de cada Comunidad Autónoma. Tienen también carácter deliberante o consultivo, y parecen especialmente llamadas a participar en todo el proceso de cooperación (incluso Planes provinciales de obras y servicios) establecido entre la Administración periférica del Estado y la Administración local. Sin embargo, y aunque legalmente autorizadas, estas Comisiones no han sido aún reglamentariamente reguladas en cuanto a su composición, organización y funcionamiento, razón por la cual debe entenderse que el Gobierno no ha ejercido la facultad legalmente amparada de crearlas. Sí en cambio se ha prolongado la vida de las antiguas Comisiones Provinciales de Colaboración del Estado con las Corporaciones locales (Disp. Transit. segunda del Texto Refundido de las disposiciones legales vigentes en materia de régimen local, RDL 18 abril 1986), de ámbito - pues- inferior al de las Comisiones Territoriales del artículo 
58-LRL, y con atribuciones limitadas aparentemente a las de cooperación del Estado a las inversiones locales ${ }^{14}$.

\subsection{Coordinación forzosa. Condicionamiento de la actividad de las Cor- poraciones locales al servicio de una acción pública coordinada}

La actividad de la Administración local en el ejercicio de sus competencias propias puede llegar a ser vinculada o condicionada a la persecución de unos objetivos y al respeto de unas prioridades, tal como dispone el artículo 59 de la Ley ${ }^{15}$.

Se debe tratar de actividades o servicios locales que transciendan el interés propio de las correspondientes entidades locales, o bien que incidan o condicionen relevantemente los de otras Administraciones o sean concurrentes o complementarios con los de éstas.

La ley sectorial, estatal o autonómica, deberá atribuir expresamente al Estado o a la correspondiente Comunidad Autónoma la facultad de coordinar en la materia a las Corporaciones locales concernidas; además, la propia Ley tendrá que precisar - con el suficiente grado de detallelas condiciones y límites de la coordinación, así como las modalidades de control que se reserve la respectiva instancia parlamentaria ${ }^{16}$.

Cuestión previa es la de saber si existe un criterio orientador para el legislador -estatal o autonómico- en la determinación de la materia o

\footnotetext{
14 La autorización legal se refiere a la creación de Comisiones de ámbito correspondiente al de la Comunidad autónoma respectiva. El Texto Refundido ha integrado el viejo artículo 130 del Texto Articulado parcial de la Ley 41/1975 (RD 3046/1977); pero en cambio se ha dejado sin aplicación hasta ahora la posible creación de Comisiones de ámbito comunitario. Esta inhibición pudiera encontrar explicación en el momento en que se aprobó el Texto Refundido (1986), cuando el artículo 58 de la Ley había sido objeto de varias impugnaciones ante el Tribunal Constitucional; pero no ahora, después de que la Sentencia 214/1989 considera totalmente ajustadas a la Constitución tales Comisiones Territoriales (FJ 20). Por el contrario, el Gobierno parece preferir las Comisiones de ámbito provincial, cuando en ellas basa el nuevo sistema de cooperación económica con las Corporaciones locales (artículo 7.1 y DA novena del cit. RD 665/1990).
}

15 El sistema normalmente se ha recogido correctamente por la legislación autonómica: art. 23 Ley 6/1986 de Castilla-León; o art. 4 de la Ley 11/87 de coordinación de Diputaciones de Andalucía, pues pretende coordinarlas mediante directrices (habrá que entender que éstas se corresponden con los planes sectoriales del art. 59 LRL, pues si no la práctica resultaría contraria a la autonomía local.

16 Precisamente por omitir tales requisitos fue considerado contrario a la autonomía local, y el Tribunal Constitucional lo anuló, el art. 118 de la Ley de Costas: STC 149/1991 (FJ 7, b). 
sector, en primer lugar; y -luego- si existe algún límite en la definición de ese interesamiento estatal o comunitario sobre competencias propias de las Corporaciones locales. No parece que haya otra regla que la de la existencia de una competencia sobre la materia en cuestión, y la voluntad del legislador para regularla; pero debe tratarse efectivamente de una materia o sector de la acción de los poderes públicos sobre la sociedad (cultura, educación, sanidad, etc.), y no de actuaciones propias de las Corporaciones locales de carácter instrumental (planificación, cooperación con otras entidades locales, etc.). No se puede declarar coordinable, por ejemplo, la facultad expropiatoria, o la de autorizar ciertas actividades a los particulares; sino que habrá que fijarse un campo de acción pública materialmente definido.

En cuanto a si existe límite en el número de sectores o materias declarables, parece claro que no. Además, resulta difícil encontrar alguna competencia local que no se encuentre incluida en el campo de eventual interesamiento del Estado o de la Comunidad Autónoma, según los casos. Pero lo que sí resultará rechazable será la pretensión -alguna vez intentada - de declarar la facultad de coordinar sobre todas o amplios conjuntos de las competencias locales. Debe procederse materia por materia.

Otra práctica absolutamente rechazable, y que choca frontalmente con la legislación estatal de régimen local —en cuyo marco se desarrollará la de las Comunidades Autónomas- es la de pretender incluir esta definición de sectores o materias en una Ley general de coordinación, y no en las Leyes sectoriales que traten cada materia 17.

Atribuida legalmente la facultad de coordinar el proceso entra en una segunda fase, siempre previa al eventual condicionamiento forzoso de la actividad local, en la cual deberá aprobarse un plan sectorial de coordinación (en adelante PSC) referido a tal sector de actividad 18.

17 Ley gallega de Coordinación de Diputaciones, 8/1989, especialmente artículos 6 y 7 , que establecen un sistema de coordinación por directrices contrario a lo dispuesto en la Ley de Régimen local. Caso más grave aún es el de la Ley 2/1991, de 14 de marzo, Castilla-La Mancha, especialmente sus artículos 1, 7 y 14. Asimismo, la Ley $2 / 1983$ de la C.A. Valenciana que en su art. 4 regula las directrices para la coordinación, y de Decretos de aplicación como el $99 / 1986$ de 30 de julio.

18 Así, en materia de servicios sociales, en Cataluña (Ley 26/85, art. 3 h.); Galicia (L. 1987 art. 10); Castilla-León, (L.18/1988, art. 35 y 36); Rioja (L. 2/1990, art. 21.1.); Extremadura (L. 5/1987, art. 18 y 20.2); Canarias (afectando a la planificación insular y municipal, en la Ley 9/1987, artículos 2.2, 12 y 13); Aragón, con un mecanismo de libre adhesión de las Corporaciones locales al plan (art.5), pero fomentada por la Comunidad autónoma (art.8), de la Ley 4/1987. En materia de sanidad, en Cataluña el Plan de Salud señala los 
El Plan sectorial de coordinación (PSC) tendrá normalmente un ámbito territorial coincidente con cada una de las Comunidades Autónomas; excepcionalmente, para materias de la competencia estatal, podrán formularse planes sectoriales de tal ámbito, con precisiones territoriales para cada Comunidad susceptibles de unirse o agregarse a la programación comunitaria (varios Decretos de transferencias a Comunidades Autónomas han iniciado ya este camino). Pues bien, si el PSC se refiere fundamentalmente a una materia competencia de la Comunidad Autónoma es obligado deducir que será finalmente aprobada por el Consejo de Gobierno correspondiente. Será el ejecutivo autonómico quien ejercite la facultad de coordinar, que la Ley sectorial le atribuye, mediante la aprobación del Plan Sectorial; y ahí se agota esa facultad, salvo la complementaria - que permanece-de verificar la adecuación de la actividad local a los objetivos y prioridades señalados.

Dentro de una concreta competencia, servicio o sector de actividad el Plan determinará el interés general o comunitario respecto del mismo; es decir, el parámetro o elemento de tal actividad local que resulte relevante a efectos de su coordinación. Por ejemplo, en la competencia municipal relativa al abastecimiento de agua a la ciudad, podría resultar del interés comunitario su grado de calidad, o la forma en que la red local conecta con la de la Comunidad. Pues bien, en tal ejemplo, el interés comunitario a los efectos de la aplicación del comentado artículo 59 se concreta en el correspondiente plan sectorial (grado tal de calidad del agua), o de una prioridad (reforzar la red urbana -por ejemplo- antes de la fecha en que se proceda a aumentar la presión en la red comunitaria).

El objetivo es el fin perseguido o el resultado que espera alcanzarse de la acción pública en la materia. No se van a coordinar actividades de las Corporaciones locales, se van a coordinar objetivos (y de todas las Administraciones sobre el territorio). No se podrá —como ya algunos pretenden-encubrir en la determinación del objetivo la proclamación de un mandato imperativo, de una orden. No se señalará lo que debe

objetivos y niveles a alcanzar (art. 63) y concede a los Consejos Comarcales nada menos que facultades de coordinación respecto de los servicios sanitarios municipales (art. 66), en la Ley 15/1990. La normativa autonómica reguladora de las aguas también establece planes sectoriales: en Canarias los planes hidrológicos regionales e insulares (L.12/1990); y en Cataluña la Ley de 1990 sobre infraestructura hidráulica crea el Programa de obras hidráulicas, que fija objetivos, relaciona obras a realizar y determina las normas reguladoras de la cooperación con las Corporaciones locales en lo referente a la ejecución de tales obras (art. 3). En cuanto a policías locales, las Leyes de coordinación de las mismas por las Comunidades Autónomas realmente lo que hacen es someterlas a normas homologadas; así, Valencia (L.1990), Asturias (L. 1988), Andalucía (L. 1989) o Extremadura (L. 1990). 
hacerse, sino hacia dónde se debe caminar; y ello siempre de forma que entre el punto de partida y la consecución del objetivo final pueda jugar la iniciativa de los agentes autónomos en la selección de las vías (de las distintas políticas) que pueden conducir a la meta.

A su vez estos objetivos pueden estar ordenados en el tiempo, en atención a la urgencia para el logro de cada uno respecto de los demás; cabe, pues, señalar dentro de las instrucciones generales para la coordinación un cuadro de prioridades.

La coordinación, como se ha dicho, es una coordinación de objetivos, no de actuaciones; y ha quedado aclarado qué debe entenderse por objetivos y qué por prioridades. No puede incluirse por ello en el contenido de la facultad de coordinar - como ya se ha pretendido- disposiciones como las siguientes:

a) Programación conjunta obligatoria ${ }^{19}$.

b) Integración obligatoria en consorcios u otros organismos

c) Acción conjunta forzosa

d) Puesta a disposición obligatoria - para su aprovechamiento fuera de la disponibilidad de la Corporación- de bienes de su propiedad 20 .

e) Vinculación forzosa de partidas presupuestarias ${ }^{21}$.

\section{${ }^{19}$ L. $26 / 1985$ de Servicios Sociales de Cataluña, art. 3 h.}

20 Se trata de la coordinación mediante la integración forzosa de los bienes, recursos o actividad de las Corporaciones locales en un "sistema" autonómico: Sistema Catalán de Salud, Ley 15/1990, art. 5 y DT $1^{\text {a }}$; art. 168.4 de la Ley Municipal de Cataluña de 15.4.87; Plan Intermunicipal de transportes, Ley de Area Metropolitana de Barcelona, 7/1987, artículos 8 a 18; y 8.a. (afectación de recursos) y 20 (aportación de solares u otros medios) de la Ley Catalana de Servicios Sociales 26/85.

21 Previsiones legales de dudosa fidelidad a la autonomía local son las siguientes: a) Obligatoria consignación en los presupuestos municipales de partidas para servicios sociales, Galicia, Ley 1987, art. 24.4; Extremadura (idem. en presupuestos provinciales), L.5/87 de 23 abril, art. 29.1.: "que garanticen el mantenimiento». b) Idem. para Cabildos (art. 23) y ayuntamientos canarios (art.24) de la L. Serv. Sociales de 1987. c) Para atención sanitaria = Ley catalana 9 de julio 1990, DT $1^{2} .2$. d) En materia de patrimonio cultural, País Vasco $1.7 / 1990$, art. 102 y 106. e) Para atender la acción social= Aragón L.7/87, art. 42 a 44. f) Coordinación financiera y presupuestaria en general, Canarias L. 14/90, art. 20, especialmente el n. ${ }^{\circ}$ 5; Galicia, unión presupuestaria para Diputaciones, en la Ley de Coordinación de las mismas de 1989, art. 13 y 14; o las aportaciones económicas que fija la Generalidad a los Ayuntamientos en materia de obras hidráulicas (art. 3 L. 1990 cit.) 
Como bien señala el artículo 10.3 de la Ley, la coordinación no afectará a la autonomía de las entidades locales; o, como señala la STC de 28 de Abril de 1983, «nunca... la coordinación general debe llegar a tal grado de desarrollo que deje vacías de contenido las correspondientes competencias...». Por ello las Corporaciones locales seguirán ejercitando sus facultades de planificación y programación, es decir, de selección de políticas, libremente, sin más limitación que la adecuación a los objetivos generales y a las prioridades establecidas (art. 59.1 in fine). Deben quedar asimismo intactas el resto de las facultades que les son propias, como - entre otras- la asignación de recursos personales y materiales, la acomodación de la propia estructura a la tarea a realizar y el control de los resultados.

La facultad de coordinar, además de la potestad de aprobar el Plan sectorial conteniendo los objetivos y las prioridades, debe alcanzar al mantenimiento de atribuciones bastantes para asegurar el respeto a tales Instrucciones Generales de coordinación. Observada la divergencia, por ejemplo, entre la actuación local y los objetivos y prioridades, el órgano facultado para coordinar podrá requerir a la correspondiente Corporación local para que ajuste a su programación o previsión conforme a aquellas instrucciones, o para que corrija las desviaciones observadas en la ejecución de sus obras o servicios. Se trata de "recordar el cumplimiento (de las obligaciones que el Plan de coordinación impone), concediéndole un plazo para ello" (art. $60 \mathrm{LRBRL}$ ).

Si, cumplido el plazo, la Corporación no ajusta o corrige su actuación descoordinada, podría utilizarse lo previsto en el tal artículo 60, que supone "la adopción de las medidas necesarias para el cumplimiento de la obligación a costa y en sustitución de la Entidad local». Más difícil por inadecuado parece la aplicación, para los fines de coordinación que analizamos, de todo el sistema de control por actos administrativos a que se refiere el Capítulo III del Título V de la Ley 22 .

\section{COORDINACION ENTRE COMUNIDADES AUTONOMAS Y ESTADO}

\section{Generalidades}

El modelo español de autonomías territoriales carece aún de un sistema eficaz para facilitar la coordinación; y si a nivel local —como acabamos de ver- esta laguna ha desaparecido, al menos en cuanto a legislación se

22 Vid. art. 136 Ley Municipal de Cataluña, 8/87. 
refiere (no tanto en su aplicación práctica), tal vacío sigue existiendo en lo tocante a las relaciones entre el Estado y las Comunidades Autónomas.

La feliz aparición de éstas en nuestro escenario institucional por virtud de la vigente Constitución de 1978, dio salida a potentes sentimientos y aspiraciones durante tanto tiempo reprimidas. Pero también generó, por virtud de la muy explicable tendencia de las Comunidades Autónomas a defender y consolidar el ámbito de poder político-administrativo recién conseguido, un recelo generalizado a las fórmulas de articulación entre Administraciones, y un ambiente poco propicio a la cooperación. Esta situación, afortunadamente, está pasando; y hoy todos admiten la necesidad de coordinarse con el vecino. Pero tal vez porque aún persiste la sospecha de que detrás de la coordinación aparece la vieja tutela, o porque la evidente complejidad de la tarea aún sigue generando dificultades técnicas, lo cierto es que todavía está por diseñarse y aplicarse un modelo satisfactorio que garantice la virtualidad de los principios de autonomía y de unidad.

No hay en nuestra Constitución, como es sabido, un sistema completo y suficiente de coordinación entre el Estado y las Comunidades Autónomas. Las referencias del artículo 149 lo son sólo a algunas materias (planificación general de la actividad económica, investigación científica y técnica y sanidad); y, además, recogen una modalidad de cooperación no voluntaria, impuesta, que resulta necesaria pero no suficiente. Y es que, salvo la importante excepción del artículo 131, no se establecen en nuestra Carta Magna mecanismos de cooperación para alcanzar voluntariamente la coordinación 23 .

En cuanto a los Estatutos de Autonomía, poco añaden a las escasas referencias constitucionales. En casi todos ellos se establece el principio de la coordinación en materia de seguridad cuando existiera policía autonómica (Juntas de Seguridad); y sólo en el Estatuto navarro podemos encontrar algunos artículos relativos a la cooperación entre esta Comunidad y el Estado (artículos 53.3, y 64 a 67), y que en su conjunto pudiera considerarse que integran en cierto modo un sistema (aunque incompleto) para la coordinación.

Esta situación trató de superarse en 1981-82 con los Acuerdos Autonómicos, incluyendo en el proyecto de LOAPA algunos artículos que

\footnotetext{
23 Sin embargo, para el Tribunal Constitucional, en su Sent. de 4 mayo 1982, la existencia de este deber general de cooperación a lo largo de todo el texto constitucional «no es menester justificar (lo) en preceptos concretos, (pues) se encuentra implícito en la propia esencia de la forma de organización territorial del Estado que se implanta en la Constitución".
} 
pretendían establecer las bases de un sistema para la coordinación entre Comunidades Autónomas y Estado (art. 9, 10 y 25); pero entre los recortes de trámite legislativo y la conocida Sentencia del Tribunal Constitucional sólo nos quedó lo relativo a las Conferencias Sectoriales y a los Decretos de transferencias. Y el legislador salió tan escaldado de todo este desastre que no ha querido intentar una regulación general de la materia; ni siquiera acogiéndose a la cobertura que ya hoy proporciona una clara e interesante jurisprudencia constitucional ${ }^{24}$.

Sí podemos encontrar, en cambio, ya en los últimos años, cierta regulación de la coordinación en algunas Leyes sectoriales, donde para la actividad de ambas Administraciones en la materia en cuestión se establecen algunos principios y reglas, o se crean organismos «ad hoc» que faciliten el funcionamiento armónico en persecución de idénticos objetivos públicos 25 . En los siguientes apartados analizaremos en detalle esta vigente legislación, aplicando la misma metodología que cuando más arriba nos referimos a la coordinación entre Corporaciones locales y otras Administraciones, y distinguiendo la coordinación voluntaria a través de la cooperación de aquella impuesta u obligatoria.

\section{Cooperación para la coordinación}

\subsection{Modalidades e instrumentos. Los convenios}

El deber general impuesto a la Administración del Estado por diversas Leyes sectoriales de intentar la coordinación cooperativa 26 no ofrece gran variedad de formas o modalidades. La Ley del Fondo de Compensación Interterritorial regula la figura de los "proyectos conjuntos de

\footnotetext{
24 Sents. del Trib. Constitucional: $n^{\circ}$. 32/1983 de 28 abril; 76/1983 de 5 agosto (LOAPA); $80 / 1985$ de 4 junio; y 144/1985 de 25 octubre. En el momento en que estas líneas se redactaron iniciaba su andadura parlamentaria el proyecto de Ley Básica de Régimen de las Administraciones públicas, al que más abajo nos referiremos, y que aborda la cuestión.

25 Más adelante citaremos artículos concretos de las siguientes Leyes: de Protección civil de 21 enero 1985; Patrimonio Histórico-artístico de 25 junio 85; de Aguas de 2 agosto 1985; de Fomento y Coordinación General de la Investigación Científica y Técnica de 14 abril 1986; de Ordenación de los Transportes terrestres de 30 julio 1987; de delegación de facultades en las Comunidades Autónomas en materia de transporte por carretera y por cable de 30 julio 1987; de Costas de 28 julio 1988; de Conservación de Espacios Naturales y de la flora y de la fauna silvestres de 27 marzo 1987; de Tráfico y Seguridad Vial de 2 de marzo de 1990 (texto articulado); del Deporte de 15 octubre de 1990; del Fondo de Compensación Interterritorial de 26 diciembre de 1990.
}

${ }^{26}$ Así por ejemplo, L. del Deporte, art. 2; o Ley Ord. Transp. Terrestres, art. 3. 
distintas Administraciones", donde teniendo la del Estado la facultad de determinación y selección -y lógicamente también la ulterior supervisión- puede asumir la autonómica la gestión y la local la ejecución de aquél ${ }^{27}$. Otra forma de intentar la coordinación es por la vía del planeamiento conjunto, ejercitando cada Administración la facultad programatoria en relación con competencias propias 28 , o participando en el proceso planificador ajeno por ser llamada o invitada a colaborar ${ }^{29}$.

El planeamiento territorial resulta obligatorio para todas las Administraciones, por lo que constituye en sí mismo un condicionamiento importante en el ejercicio por éstas de sus competencias propias, y en ocasiones puede llegar a suponer en la práctica un verdadero instrumento de coordinación forzosa. Además, cuando las actividades públicas de diferentes Administraciones se desarrollan sobre un mismo territorio la cooperación (coordinación voluntaria) resulta especialmente recomendable, y en ocasiones imprescindible. $Y$ dado que tal despliegue de actividades sobre el territorio, con determinación entre otros de sus aspectos temporales, se realiza a través de instrumentos de planeamiento territorial (documentos de ordenación urbana y territorial), la coordinación de los mismos servirá para evitar interferencias e inconvenientes y contribuirá al logro del interés general. Queremos destacar por su importancia la técnica de la planificación participada, donde el ente competente para preparar y aprobar el Plan deberá recabar el informe de las otras Administraciones con competencias en el territorio para armonizar sus previsiones con las

27 Ley 29/1990, de 26 dic., art. 8.

28 Ley del Fondo, art. 6; Ley de Tráfico, art. 8, donde se regula la utilización de "planes de actuación conjunta", elaborados y propuestos por el Consejo Superior y aprobados por el Gobierno; o la coordinación por integración de programas científicos de las Comunidades Autónomas en el Plan Nacional de Investigación Científica y Desarrollo Tecnológico, art. 6.2. c. de la Ley 14.4.86. Una forma de coordinación a través de planes se regula en la Ley General de Sanidad de abril de 1986, ya sea mediante la voluntaria aprobación por ambas Administraciones de planes conjuntos (art. 71), ya a través del Plan Integrado de Salud (art. 74), que aunque aprobado finalmente por el Gobierno recoge en un documento único planes antes adoptados por cada Comunidad Autónoma en ejercicio de sus competencias propias, si bien forzosamente ajustados a los criterios generales de coordinación establecidos como obligatorios por el Estado (art. 70): como más adelante veremos, constituye éste de la Ley General de Sanidad un buen modelo de utilización al tiempo de técnicas de coordinación voluntaria y de coordinación forzosa.

29 Acerca de la formación en común de planes y programas, vid. MUÑOZ MACHADO, «Derecho público...», op.cit., I, págs. 237 a 239. Nosotros queremos destacar la importancia y el carácter imperativo del art. 58.2 pf.2 LRL, al establecer el deber por parte de la Administración que planifica de otorgar a las restantes «una participación que permita los intereses públicos afectados». 
del informante. Las alegaciones del informe, o las derivadas de la consulta o del encuentro interadministrativo, normalmente no vincularán al planificador; pero en ocasiones se ha establecido legalmente la obligación de intentar -incluso alcanzar - un acuerdo común, por lo que en tales casos no podrá aprobarse el plan hasta que conjuntamente se alcance esta voluntad común 30 .

Siendo importantes cuantos se acaban de exponer, el instrumento más utilizado para la cooperación entre el Estado y las Comunidades Autónomas es el convenio. Aunque no existe referencia constitucional al mismo, y sólo un Estatuto de Autonomía lo menciona expresamente 31, la legislación sectorial comienza a darles acogida 32 , y en la práctica de las relaciones interadministrativas resultan cada vez más frecuentes. Afortunadamente la nueva Ley de Régimen Jurídico de las Administraciones Públicas dedica los artículos 6 y 8 a su regulación específica. En los últimos tiempos el Gobierno ha hecho aprobar a través de la Comisión Delegada para la Política Autonómica, unas normas para regular la forma de adopción, que brevemente pasamos a describir 33:

a) Elaboración y aprobación: Normalmente diseñado en sus líneas generales a partir de una experiencia relacional anterior (con una concreta Comunidad Autónoma o con todas), la unidad administrativa promotora redacta el convenio, "tendiendo a contemplar de forma completa un área sectorial específica y a comprender, con el mayor grado de integración posible, las diversas técnicas en colaboración". En el caso, el más frecuente, de implicar también obligaciones financieras para la Administración del Estado, debe asegurarse la debida coordinación con la política de inversiones de cada Departamento en el marco de las directrices del Gobierno ${ }^{34}$.

30 Vid. L. FAJARDO SPINOLA, "Coordinación de la actividad de las diferentes Administraciones sobre la costa», comentando la Sent. TC 149/1991 de 4 de julio, en RAP n ${ }^{\circ} 128$, 1992, pág. 235.

31 Est. de Autonomía de Navarra, art. 65: «... celebrar convenios de cooperación para la gestión y prestación de obras y servicios de interés común».

32 Vid., entre otras, la Ley de Ord. Transp. terrestres, art. 5.2. Vid. E. ALBERTI ROVIRA, "Los convenios entre el Estado y las Comunidades Autónomas", Anuario de Derecho constitucional y Parlamentario, Murcia 1990, n. 2 , págs, 71 a 93.

33 Todos estos requisitos aparecen ya en las primeras regulaciones del Consejo de Ministros de 13 septiembre 1984 y 18 junio 1985. La última es la Res. 9 marzo 1990.

34 Lo acordado por vía de convenio en absoluto puede alterar el reparto constitucional de competencias, pues "resulta irrelevante para determinar el ordenamiento competencial en lo material» (STC 71/83, de 29 de julio). Así lo determina además el art. 8.1 LRJAP-PAC. 
La mayor parte de los convenios han sido preparados como contratos de adhesión, con vocación de incorporar - salvo excepciones- a todas las Comunidades Autónomas; en tales casos de suscripción generalizada que incluyen compromisos financieros para la Administración del Estado, se deberán presentar como Convenio-Programa (el programa es el soporte básico sobre el que se insertan los singulares convenios con cada una de las Comunidades Autónomas). A veces, en cambio, el convenio responde a la singularidad de una particular relación de la Administración del Estado con una concreta Comunidad Autónoma; y en ocasiones incluso la cobertura del convenio se reduce aún más, en aquellos casos en que se pretende regular la cooperación en relación con una única tarea (realización concreta de una única obra pública, p.ej.), por lo que su vigencia concluye al finalizar o culminarse aquélla 35 .

El proyecto de convenio se remite a la Secretaría de Estado para las Administraciones Territoriales, que lo informa en relación con su adecuación a la política gubernamental sobre cooperación con las Comunidades Autónomas; luego - con carácter previo a la firma por el Ministerio promotor, o por el Presidente o Director del organismo autónomo correspondiente- deberá ser autorizado expresamente por la Comisión Delegada del Gobierno para Política Autonómica. El mismo procedimiento se seguirá cuando se pretendan modificaciones sustanciales de un convenio en vigor. Los convenios serán comunicados al Senado, y publicados en el B.O.E. y en el Diario Oficial de la Comunidad Autónoma (art. 8.2. LRJAP-PAC).

b) Contenido: La parte más destacada de su contenido se ocupa de las actuaciones o prestaciones públicas que se coordinan, ya sea describiéndolas expresamente 36 , ya por referencia a un plan marco anterior ${ }^{37} \mathrm{o}$ al contenido de un informe en la materia que se acepta por

35 Entre otros muchos, Convenio entre la D.G. Obras Hidráulicas, la C.A. de Canarias y dos Ayuntamientos para la construcción de una potabilizadora de agua del mar. Res. 28.5.90. La Ley 30/1992 distingue dos tipos básicos de Convenios: el de Conferencia Sectorial y el de colaboración. La diferencia entre ellos no parece estar sólo en la forma de originarse los primeros, sino tal vez también en su ámbito territorial: los primeros podrían ser calificables de multilaterales, y de bilaterales los segundos.

36 Convenio Programa Andalucía-Ministerio de Trabajo, sobre prestaciones básicas en materia de servicios sociales, Res. 25.5.88, cláusula 2 . A veces, la descripción de actividades incluye una escala de prioridades para su ejecución, como en la cláusula 2 del Conv. M. Sanidad C.A. Extremadura para el desarrollo de la atención primaria a la salud, aprobado por Res. 17.12.87.

37 El plan marco resultó aprobado por $\mathrm{RD}$ anterior, como en el caso del Conv. con Cataluña para la contratación temporal de trabajadores desempleados de 27 de julio 1988, o para el Conv. con Canarias sobre educación compensatoria de 6 sept. 88. 
ambas partes 38 , ya recogiendo en su integridad en el propio convenio el desarrollo pormenorizado de los programas en que aquellas actividades deben encajar.

A veces el convenio incluye una minuciosa normativa de autorregulación convencional para la organización y funcionamiento de ciertos servicios públicos, afectando en consecuencia a todo el personal y medios adscritos a los mismos, «independientemente de la titularidad de los centros donde actúen o de la relación laboral de sus miembros con una u otra Administración 39.

También suele incluirse en el convenio la descripción de los mecanismos o técnicas para la coordinación que vayan a utilizarse; la determinación de los medios financieros, personales y materiales que cada Administración aportará; así como su vigencia, el sistema para resolver los conflictos y el modo de denunciarlo.

Tanto las normas dictadas con carácter general por el Gobierno, como la mayoría de los convenios, conceden gran importancia al seguimiento de la ejecución del acuerdo y a la evaluación de sus resultados. Para ello se establece en la mayoría de los casos una Comisión Mixta, de carácter bilateral ${ }^{40}$ o multilateral ${ }^{41}$. Cuando se cree un órgano mixto de vigilancia y control, éste resolverá los problemas de interpretación y cumplimiento; en cualquier caso, los litigios que surjan podrán someterse al conocimiento del orden jurisdiccional contencioso-administrativo, y en su caso al Tribunal Constitucional (art. 8.3. LRJAP-PAC).

${ }^{38}$ Conv. de asistencia sanitaria con Asturias, Res. 22.12.87.

${ }^{39}$ Conv. cit. con Extremadura (17.12.87), cláusula primera.

${ }^{40}$ Con variación denominaciones: Comisión Mixta, Comisión paritaria, comité de enlace; a veces con funciones de planificación de la actividad coordinadora (Conv. ICONAAsturias, 3 julio 1987, cláusula 4); en ocasiones se complementan con la presencia, además, de diversos agentes públicos o privados (Conv. M. Educación-Madrid, sobre dinamización cultural, cláusula 5). Cuando, a partir de este seguimiento, se evidencia el incumplimiento por una de las partes de lo convenido, el conflicto no es de fácil solución. E. ALBERT ROVIRA, cit., págs. 88 a 90, admite la posibilidad de control judicial sólo en ciertos casos. Vid. también A. JMENEZ BLANCO, "Las relaciones...", cit., pág. 294.

41 Se establece una Comisión de seguimiento del convenio para toda España (Por ejemplo, Conv. Programa de prestaciones básicas en materia de servicios sociales, etc., 25.5.88, cláusula 9; o Conv. programa para situaciones de necesidad, aprobado en relación con Aragón por Res. 4 noviembre 1987, cláusula 8). 


\title{
2.2. Organización para la coordinación
}

Como acabamos de ver, de la práctica convencional en las relaciones Estado-Comunidades Autónomas ha surgido en los últimos años multitud de organismos y comisiones paritarias cuya finalidad principal consiste en facilitar la coordinación voluntaria entre ambas instancias. Pero no sólo los convenios han creado estos instrumentos de relación; también la legislación sectorial del Estado ha recurrido a esta técnica armonizadora en los últimos años, reclamando la participación de las Comunidades Autónomas en los comités de los que la Administración central se ha dotado para la elaboración de las políticas a desarrollar en cada materia ${ }^{42}$, y asimismo la legislación de las Comunidades Autónomas 43 .

Con carácter más general y permanente se han establecido dos organismos para la coordinación voluntaria: las Conferencias Sectoriales y las Comisiones Bilaterales ${ }^{44}$. También deberíamos mencionar a las

\begin{abstract}
42 Así, la Ley de Conservación de Espacios Naturales y de la Flora y Fauna salvajes de 27 de marzo 1989, en su art. 36 crea la Comisión Nacional para la protección de la naturaleza, donde participan Estado y Comunidades Autónomas, y que informa preceptivamente de los proyectos de directrices para el acción protectora. O la Ley de Tráfico y Seguridad Vial, cit., que "para garantizar la coordinación de las competencias de las diferentes Administraciones públicas» ha creado en su art. 8 el Consejo Superior de Tráfico, y una Comisión en cada Comunidad. Con idéntica finalidad, la Ley de Ordenamiento de los Transportes terrestres, cit., crea la Conferencia Nacional de Transportes, y la adjunta Comisión de Directores Generales; o la Comisión Nacional de Protección Civil, y las establecidas en cada Comunidad, por L. 21.1.85; y también podrían citarse las comisiones provinciales de planificación y coordinación de inversiones, y las regionales de calificación, coordinación y seguimiento, ambas para el Plan de Empleo Rural, reguladas por Reales Decretos de 11 de octubre 1990 y 18 de enero 1991.
\end{abstract}

43 Citaremos, entre otro muchos, sólo el caso de la Comisión de Ordenación del territorio del País Vasco (art. 29 Ley 4/1990, de 31 marzo), donde participan todas las Administraciones para facilitar la elaboración y aplicación coordinadora de los criterios de ordenación territorial.

44 No hay aún una norma en la que apoyar la existencia y ordenar el funcionamiento de las bilaterales (se regulan por lo establecido en el acta fundacional); pero existen y vienen funcionando bien. En la comparecencia de 23 abril 1991 en el Congreso de los Diputados, el Ministerio para las Administraciones Públicas afirmaba que «estas Comisiones Bilaterales han servido como mínimo para canalizar pretensiones de cada Comunidad Autónoma, de una forma ordenada y razonable, para estudiarlas y, en caso, discutirlas; y han servido para prevenir y solucionar conflictos jurídicos y administrativos..." En cuanto a las Conferencias Sectoriales, para el Ministro «han supuesto el embrión de lo que debe ser el instrumento de participación de las Comunidades Autónomas en la formación de la voluntad del Estado...» (Recuérdese que las Conferencias Sectoriales se crean por el art. 4 Ley 12/83, de 14 de octubre. Sobre organización para la cooperación vid. G. Fdez. GARRERES, "El principio de colaboración Estado-Comunidades Autónomas y su incidencia orgánica», Rev. Vasca Adm. Pública, 6/1983, págs. 213 s.s.) A las Conferencias Sectoriales se refiere expresamente el art. 5 Pyto. Ley Rég. Juríd. Ad. Públicas, que en estos momentos estudian y debaten las Cortes Generales. 
Comisiones Mixtas de Transferencias Estado-Comunidades Autónomas, que de hecho han elaborado y aprobado para competencias concretas un sistema de coordinación entre ambos en el subsiguiente ejercicio de las transferidas y de las retenidas.

Tanto las comisiones sectoriales como las generales para la coordinación tienen en común el carácter no vinculante (en sentido jurídico) de sus acuerdos; pero en ellas se adoptan acuerdos políticos que todos se comprometen a aplicar en el ejercicio de sus respectivas competencias propias, y que armonizan criterios sobre objetivos comunes, sobre ritmos de ejecución, sobre prioridades o sobre modos e instrumentos de la acción pública en una materia o sector de actividad. Además, lo acordado en una comisión puede ser objeto de convenio (art. 5.3 del Pyto. de Ley Reg. Juríd. Adm. públicas, citado), con lo que se transforma en jurídicamente obligatorio para las Administraciones que lo suscribieron. En cualquier caso, estas mesas de acuerdo, estos lugares de encuentro, constituyen sin duda unos potentes y eficacísimos mecanismos para la coordinación.

Finalmente, queremos recordar la importancia de las facultades de coordinación que la propia Constitución asigna al Delegado del Gobierno, en las relaciones de la Administración periférica del Estado con la de la Comunidad Autónoma respectiva. Aunque la Ley reguladora de esta institución poco más dice al respecto (art. 6 de la Ley 17/1983, de 16 de noviembre), el Delegado del Gobierno está facultado para tomar la iniciativa en la puesta en marcha de cuantos mecanismos administrativos resulten adecuados para facilitar la coordinación entre ambas Administraciones, y está obligado a hacer un seguimiento constante de esta relación y a favorecer los procesos de encuentro.

\section{Coordinación forzosa}

Este tipo de coordinación, que como hemos dicho resulta en nuestro sistema excepcional y supone el final de un proceso de cooperación que no dio resultado, comporta una imposición sobre el ente coordinado en el ejercicio de su propia competencia, para hacer que se dirija a los objetivos generales y que respete las prioridades que lo harán converger con la actuación de otras Administraciones. La coordinación forzosa, cuando existe, se dirige pues a armonizar el resultado de la acción administrativa del coordinado, y no a imponer el tipo de medios para alcanzarlo. Entendemos, además, que siempre que se atribuye expresamente a un ente público la competencia para coordinar nos encontramos ante una facultad ejercitable incluso contra la voluntad o frente a la reticencia del coordinado; y no sólo ante el 
mandato de coordinarse con otros entes actuantes, pues para ello no haría falta tal expresa mención. Es decir, cuando se atribuye a un ente la competencia para coordinar se incluye también la que denominamos coordinación forzosa.

Para la localización de supuestos de coordinación forzosa entre el Estado y las Comunidades Autónomas es evidente que nos limitaremos a los que la Constitución o el respectivo Estatuto establezcan, pues suponiendo este tipo de coordinación el eventual recorte de competencias propias de entes dotados de autonomía constitucionalmente definida y garantizada, cualquier otro supuesto externo al bloque de constitucionalidad resultaría evidentemente anticonstitucional. Ya vimos que la Constitución sólo atribuye al Estado la facultad de coordinar en materia de planificación general de la economía, investigación científica y técnica, y sanidad. Se trata de competencias exclusivas del Estado; con la particularidad, además, de que suponen la existencia de competencias propias de otras Administraciones en la misma materia: precisamente las competencias llamadas a ser coordinadas. No debe tampoco excluirse la posibilidad de que en ciertos casos sean las Comunidades Autónomas las titulares de facultades de coordinación que comprometan incluso la actividad de la Administración del Estado, tal como ocurre con la ordenación del territorio, a la que más abajo nos referiremos.

Centrémonos en primer lugar en el análisis de las facultades de coordinación general que la Constitución atribuye en exclusiva al Estado ${ }^{45}$.

\footnotetext{
45 En algunos supuestos la Constitución atribuye al Estado junto con la facultad coordinadora la competencia para fijar las bases del régimen jurídico en la materia, aunque según reiterada jurisprudencia TC se trata de competencias distintas: STC 32/1983, de 28 abril (FJ 2); 42/1983, de 20 mayo (FJ 3) y 144/1985, 25 octubre (FJ 4). Sin embargo, a nuestro entender tanto la regulación de las bases como el ejercicio de la facultad coordinadora producen efectos integradores de partes real o potencialmente diversas, por lo que a primera vista no resulta tan fácil su diferenciación. Pensamos que no está la diferencia en el soporte formal de la competencia ejercida, pues no siempre para la fijación de las bases se utiliza una norma (legal o reglamentaria); mientras que en algún caso la coordinación se alcanza mediante una disposición de carácter general: vid., pfo. 2 del FJ 4 de la citada STC 144/85. A nuestro modo de ver la diferencia más clara se encuentra en que la competencia de dictar las bases se orienta fundamentalmente a la formación del sistema que ordena una materia determinada (aspecto estático o sustantivo), mientras la de coordinar se manifiesta cuando el tal sistema se pone en movimiento (aspecto dinámico u objetivo) y se pretende que en su funcionamiento las diversas partes se mantengan dentro del conjunto del mismo. Además, la de fijación de bases se agota con su determinación en los niveles legal, reglamentario e incluso ejecutivo; mientras que la coordinación permite intervenciones sucesivas indefinidas, siempre que la integración de la diversidad en el sistema o conjunto esté en peligro. Finalmente, las anteriores consideraciones, y el hecho de que no siempre la competencia exclusiva del Estado para coordinar viene acompañada de la de fijar las bases en la materia, debe conducirnos a afirmar que para ejercer la facultad coordinadora no viene el Estado obligado previamente a declarar su carácter básico.
} 
En primer lugar, se atribuye al Estado la competencia exclusiva para la coordinación de la planificación general de la economía (149.1.13). La adjetivación como general de la planificación a coordinar no debe entenderse opuesta a sectorial, sino más bien para destacar su incidencia en el conjunto del sistema económico nacional y en referencia al ámbito geográfico de toda España ${ }^{46}$. «La competencia estatal en cuanto a la ordenación general de la economía - se afirma por el Tribunal Constitucional en el FJ 2 de la Sentencia 186/1988- responde al principio de unidad económica y abarca la definición de las líneas de actuación tendentes a alcanzar los objetivos de política económica global o sectorial fijados por la propia Constitución, así como la adopción de las medidas precisas para garantizar la realización de los mismos. La necesaria coherencia de la política económica exige decisiones unitarias que aseguren un tratamiento uniforme de determinados problemas en orden a la consecución de dichos objetivos y evite que, dada la estrecha interdependencia de las actuaciones llevadas a cabo en las distintas partes del territorio, se produzcan resultados disfuncionales y disgregadores».

Una ya abundante jurisprudencia del citado Tribunal viene dando amparo a normas jurídicas relativas a diferentes campos de acción pública donde se atribuye al Estado la facultad de coordinar la planificación en la materia ${ }^{47}$. La coordinación consistirá en la "fijación de medios y sistemas de relación que hagan posible la información

\footnotetext{
46 Como señala GARCIA DE ENTERRIA, en la práctica totalidad de los sistemas federales la competencia planificadora que afecta a la estabilidad (índice de inflación, tasa de desempleo, etc.) o a la redistribución se considera siempre de la competencia propia del Estado central ( (Distribución de las competencias económicas entre el poder central y las autonomías territoriales en el Derecho comparado y en la Constitución española. Estudio preliminar", Madrid, 1980, pág. 23); y de esta manera se podrá garantizar "la unidad del espacio económico nacional y los resortes de política económica que la protegen y cuidan de su desarrollo homogéneo y además solidario" (pág. 22). Sin duda ésta es la generalidad que se predica de la planificación coordinable por el Estado, por lo que también incluirá los supuestos sectoriales cuando se manifieste esta relación con el conjunto del sistema económico nacional. Así lo ha entendido también la jurisprudencia del TC en varias resoluciones que citamos enseguida.
}

47 Agricultura de montaña (STC 144/1985, de 25 oct.); ayudas a jóvenes agricultores (STC 95/1986, 10 julio); ayudas al turismo (STC 88/1987, 2 junio); protección de la vid (STC 186/1988, 17 oct.); ayudas y subvenciones en agricultura y ganadería (STC 201/1988, 27 oct.); recursos hidráulicos (STC 227/1988, 29 NOV.); o cultivos marinos (STC 103/1989, 8 junio, especialmente FJ 9). Otro caso de sector de la economía sobre el que puede el Estado ejercitar facultades de coordinación de la planificación autonómica es en el relativo al transporte por carretera y cable, bien que aquí no a partir del art. 149.1.13 CE, sino por tratarse de competencia estatal exclusiva delegada en Comunidades Autónomas; aquí la Administración del Estado puede dictar "reglas de coordinación" a las cuales quedará sujeto el ejercicio de las facultades delegadas (art. 16 LO 5/1987, de 30 julio), de tal manera que en caso de incumplimiento podrá revocarse la delegación o suspenderse el acto o acuerdo de la Comunidad contrario a aquéllas reglas. 
recíproca, la homogeneidad técnica en determinados aspectos y la acción conjunta» (STC 144/1985) de quienes ostentan la facultad de planificar la economía de cada materia. La medida coordinadora podrá contenerse a su vez en un documento de planificación general que «establezca líneas de actuación" (STC 186/1988) sin agotar toda la capacidad planificadora en la materia (STC 227/1988); o bien consistir en un acto previo a la planificación misma, que - por ejemplo- se limite a señalar el ámbito material o geográfico de ejercicio por las Comunidades Autónomas de sus facultades planificadoras (STC 144/1985). En cualquier caso, esta competencia estatal de coordinación general «resultará excedida, con la consiguiente invasión competencial, si la especificación (del destino de las subvenciones) se realiza en tal grado de concreción y detalle que, no siendo imprescindible para asegurar el objetivo de la planificación, se priva a las Comunidades Autónomas de todo margen para desarrollar... una política propia» (STC 201/1988). El procedimiento coordinador normalmente favorecerá la participación de las Comunidades Autónomas mediante informes o actos previos (STC 144/1985, FJ 5); pero evidentemente ante el incumplimiento de la directriz coordinadora (sea cual fuere la forma que ésta hubiese adoptado) por la parte autonómica, el Estado podrá imponer su criterio por la fuerza. La diferente naturaleza del acto autonómico de planificación indisciplinado (Ley territorial, reglamento, medida ejecutiva), o la inactividad planificadora en su caso, comportarán caminos también diferentes por parte del Estado para su reconducción al sistema unitario (los más practicables del artículo $153 \mathrm{CE}$, o el más drástico del artículo 155). La dureza de este final conducirá evidentemente a intentar previamente la coordinación por la vía de la voluntaria cooperación, o por la aplicación de técnicas intermedias como la de establecer mecanismos que dificulten la planificación discrepante y alienten (incentivos) la concordante ${ }^{48}$.

Hasta aquí nos hemos referido a la planificación sectorial de la economía; todo lo dicho, evidentemente, resulta aplicable a la hipótesis de una ordenación más universal de la economía. La propia Constitución, en el artículo 131, contempla esta posibilidad, aún no aplicada. Lo que sí se da, en cambio, es la planificación para el desarrollo económico dentro del marco establecido por la política regional de la CEE, a través de diversos instrumentos de programación territorial coordinados e integrados en el ámbito más amplio del conjunto

\footnotetext{
48 Uno de estos sistemas intermedios se encuentra en la vigente Ley de Costas, tal como la interpreta la STC 149/1991, a la que hemos dedicado un comentario en otro lugar. Vid. FAJARDO SPINOLA, "Coordinación de la actividad de las diferentes Administraciones sobre la costa», REDA, 1992.
} 
español por el Gobierno de la Nación 49 . A nuestro modo de ver, las facultades gubernamentales en este supuesto se basan fundamentalmente en el citado artículo 149.1.13 CE. Finalmente, medidas no sectorializadas de carácter horizontal adoptadas a iniciativa del Gobierno a través de los Presupuestos Generales del Estado de cada año, o de decisiones del Ministerio de Hacienda o del Banco de España, para controlar la evolución de las grandes magnitudes económicas (inflación, tasa de desempleo, política monetaria, etc.) podrían considerarse como instrumentos de coordinación utilizados al servicio de la unidad del sistema económico y amparables en la competencia exclusiva tan comentada del artículo 149.1.13 CE. También aquí nos encontramos ante supuestos de coordinación forzosa.

Otro supuesto de atribución constitucional al Estado de la competencia exclusiva para coordinar a los entes territoriales referido a la investigación científica y técnica. La Ley 13/1986 de Fomento y Coordinación de la Investigación Científica y Técnica establece unos mecanismos de coordinación, en desarrollo del citado artículo constitucional, que funcionan sobre la base de la libre adhesión de las Comunidades Autónomas al sistema estatal de conjunto. El instrumento principal de coordinación por parte del Estado es el Plan Nacional de Investigación Científica y Técnica (art. 1). Las Comunidades Autónomas pueden solicitar la incorporación al mismo de sus programas propios (art. 6.2.c.), y sólo entonces se someterán a la acción planificadora y coordinadora de la Comisión para la Investigación Científica y Técnica (art. 7). Existe, además, un órgano de encuentro Estado-Comunidades Autónomas para facilitar la coordinación forzosa, y ello se explica por la naturaleza de la actividad de que se trata (donde la libertad de orientación es fundamental); pero aunque de libre adhesión, el cuadro de objetivos básicos y directrices de investigación fijados por la Administración del Estado

\footnotetext{
49 Ya el Programa Económico a Medio Plazo 1984-87, ante la realidad de una iniciativa planificadora descentralizada, urgía al establecimiento de algún sistema de coordinación de los programas de desarrollo regional. La integración de España en la CEE, y la consiguiente aplicación en nuestro país de los fondos Estructurales, aceleró la exigencia de contar con un planeamiento nacional y regional «ad hoc». Actualmente resultan de aplicación los Reglamentos comunitarios números 2052/88, 4253/88 y 4254/88, del Consejo, que diseñan un sistema basado en Planes de Desarrollo Regional (PDR) coordinados e integrados en el Plan de Desarrollo Regional de España 19891993 (vid. pág. 227, Edic. marzo 1989, Secret. de Estado de Hacienda). En relación con la coordinación de estos PDR, vid. HERNANDEZ ARMENTEROS y otros, "Una valoración de la coordinación y coherencia de los objetivos de los PDR", Rev. Est. Territoriales, sept.-dic. 1987, págs. 121-138; y CAPDEVILA SALVA, "La planificación y el sector público. Su articulación a nivel estatal, autonómico y local", Rev. Hacienda Aut. y Local, mayo-agosto 85 , págs. 217-280.
} 
de hecho vincula la actividad desplegada por las Comunidades Autónomas en la materia 50 .

El tercer supuesto de atribución de competencia exclusiva al Estado para coordinar (149.1.16) se refiere a la sanidad: «bases y coordinación general de la sanidad». La Ley General de Sanidad de abril de 1986 tiene casi toda ella la condición de norma básica, y —además- dedica amplio tratamiento al sistema de coordinación general en la materia. Aquí nos ocuparemos solamente de aquella calificable como forzosa.

Para alcanzar la coordinación de las actuaciones de las Comunidades Autónomas entre sí y con el Estado en materia sanitaria éste sujetará el contenido de los planes autonómicos mediante un mecanismo legalmente establecido y que se desarrolla en dos fases:

a) En la primera el Estado fijará unos criterios generales de coordinación, a los que el planeamiento sanitario autonómico habrá de ajustarse. Tales criterios contendrán objetivos, prioridades y estándares de calidad relativos a aspectos orgánicos, funcionales y de personal del sistema sanitario, pero sobre todo concernientes a las características y condiciones del servicio que el ciudadanos recibirá (art. 40, 43.2 y 70). La Administración del Estado comprobará la adecuación de los Planes de Salud de las Comunidades Autónomas a estos criterios generales de coordinación; en caso de contradicción entre Planes y criterios advertirá de ello a la Comunidad Autónoma correspondiente (art. 43.4), y si así y todo persiste la situación de incumplimiento por parte de ésta, "el gobierno - de acuerdo con lo establecido en la Constitución- requerirá formalmente al órgano competente de la Comunidad Autónoma para que adopte las medidas precisas" (art. 43.5). Nos encontramos, pues, ante un caso típico de coordinación forzosa.

b) En una segunda fase, sin embargo, este mecanismo de coordinación forzosa se combina con elementos de voluntaria cooperación, al facilitar la incorporación al Plan Integrado de los Planes Sanitarios de las Comunidades Autónomas. Estos deberán acomodarse en cuanto a grandes objetivos y prioridades al marco coordinador fijado por el Estado, pero por lo demás contendrán los elementos de una política sanitaria libre y autónomamente elaborada por cada Comunidad 51.

50 Vid. por ejemplo el Programa sectorial de investigación y desarrollo agrario y alimentario: objetivos básicos y directrices generales de investigación, aprobado por OM 19 Sept. 1988, e incorporado al Plan Nacional de Investigación.

51 La incorporación de los planes nacionales y autonómicos al Plan integrado produce, a tenor de lo dispuesto en el art. 76.2 de la Ley de Sanidad, "la obligación correlativa de incluir en los presupuestos de los años sucesivos las previsiones necesarias para su 
La Ley de Sanidad abre además la posibilidad de que el Estado, para ejercitar sus facultades de coordinación general fije otros medios y sistemas de relación (no determinados), que al facilitar la información recíproca, la homogeneidad técnica o la acción conjunta, produzcan el tan buscado efecto coordinador. A cualquier «medio o sistema de relación" podrá acudir el Estado, siempre que no llegue a limitar innecesariamente e inmoderadamente la competencia propia de la Comunidad Autónoma 52.

Por lo que hemos visto, el sistema de coordinación forzosa de la Ley General de Sanidad, combinado con ciertos ingredientes de cooperación, constituye el modelo más completo y desarrollado en nuestro Derecho vigente; como más adelante veremos, sus elementos básicos podrían servir para construir un sistema general aplicable — con la flexibilidad que cada caso requiere - a los diferentes campos de acción pública.

Por lo demás, otras Leyes sectoriales también regulan supuestos de coordinación forzosa por el Estado de la actividad de las Comunidades Autónomas; así, en materia de protección civil 53 , de tráfico y circulación ${ }^{54}$, de seguridad pública 55 , de protección de espacios naturales ${ }^{56}$, o de transportes terrestres 57 .

financiación, sin perjuicio de las adaptaciones que requiera la coyuntura presupuestaria". Tan sorprendente disposición sólo puede justificarse si se limita a una pura recomendación para el futuro redactor del proyecto de presupuesto; pues no cabe pensar que un Plan aprobado por el Gobierno vincule a las Cortes Generales o al Parlamento de cada Comunidad. Vana pretensión. Vid., para la cuestión de la relación entre previsiones plurianuales y técnica presupuestaria, pero manifestándose contrario a la vinculación, J. ANTON PEREZ, "Ley del Plan y Ley de Presupuestos», Rev. Hac. pública esp., número 11.

52 El texto de la Ley General de Sanidad se inspira -incluso siguiéndolo literalmenteen el FJ 2 de la STC 32/1983, de 28 abril, que se refiere a la competencia para la coordinación general de la sanidad del art. 149.1.16 CE.

53 La Ley de 21 de enero de 1985 otorga al Gobierno facultades coordinadoras sobre las Comunidades Autónomas, a las que puede requerir para que cumplan las obligaciones correspondientes (art.16).

54 Coordinación a través de directrices básicas y esenciales para la formación y actuación de los agentes de la autoridad en materia de tráfico y seguridad, tanto de Comunidades Autónomas como de Corporaciones locales, según art. 8 RDL 2.3.90, número 339/1990, que aprueba el Texto articulado de la Ley de Tráfico, Circulación de vehículos de motor y Seguridad vial.

55 Así se deriva de los propios Estatutos de Autonomía de aquellas Comunidades Autónomas donde existiera policía autonómica, a través de las Juntas de Seguridad.

56 Coordinación forzosa a través de directrices aprobadas por el Gobierno de la Nación (criterios y normas generales de carácter básico que regulan la gestión y uso de los recursos 
Finalmente, queremos referirnos a unos supuestos bien diferentes de coordinación forzosa, tendentes a garantizar que las distintas Administraciones que operan sobre el territorio se sometan al conjunto en lo tocante a la localización física de sus actuaciones. Sin duda alguna la función pública que más claramente está dirigida a coordinar a las Administraciones que actúan sobre un mismo lugar es la ordenación del territorio. Debe precisarse, sin embargo, que la ordenación del territorio puede lograr la coordinación de la actividad administrativa de aquéllas sólo respecto de su incidencia territorial (es decir, del "dónde», o del "qué en relación con el dónde»: usos por zonas); pero la ordenación del territorio no integra la función coordinadora respecto de los objetivos, ni de las prioridades, ni de los ritmos de ejecución aplicables por Administración distinta de la que ordena el territorio. Todas las Comunidades Autónomas tienen competencia exclusiva en la materia 58 , y muchas de ellas han establecido ya mecanismos de coordinación de otras Administraciones (también de la estatal) en el referente territorial de su actividad, por lo que consideramos interesante hacer una exposición sistemática de los aspectos de tal legislación autonómica más referidos al presente estudio.

Todas las Comunidades Autónomas que han legislado en la materia se reservan como propia y no compartida la competencia para determinar «el marco de referencia territorial para la formulación, desarrollo y aplicación de las políticas sectoriales de las distintas Administraciones» 59.

naturales), a las cuales se someterán los PORN autonómicos (art. 8 Ley Conservación Espacios Naturales, cit.).

57 El Gobierno de la Nación fija «objetivos de la política general de transportes... para asegurar su coordinación" o para garantizar las necesidades de la defensa nacional y de la protección civil (art. 6, 29, 30 y 31 de la Ley 16/1987 de 30 de julio, de Ordenación de los Transportes Terrestres).

58 Estatutos de Autonomía de Euskadi (art. 10.31); Cataluña (art. 9.9); Galicia (art. 27.3); Andalucía (art. 13.8); Navarra (art.44.1); Valencia (art. 31.9); Canarias (art.29.11); Asturias (art. 10.1.b); Cantabria (art.22.3); La Rioja (art.1.8); Murcia (art.10.1.b); Aragón (art.35.1.3); Castilla-La Mancha (art.31.1.b); Extremadura (art.7.1.2); Baleares (art.10.3); Madrid (art.26.3); y Castilla-León (art.26.1.2).

59 Valencia: Ley 6/1989, de 7 julio, art. 4.10; País Vasco, L. 4/1990, de 31 mayo, art. 5.b.; Asturias: L.1/1987, de 30 marzo, de coordinación y ordenación territorial, art. 10.1.14 y 6.2.c.; Baleares, L. de 1 abril 1987, art.6, 10, 11 d, 13 y 23; ley Urbanística de Cataluña, de 12 julio 1990, o la Ley para la Conurbación de Barcelona, de 4.4.87, art. 6. Normalmente estas Leyes regulan una interesante figura de planes sectoriales que cumplen la doble función de fijar el marco para la actuación sobre el territorio y de establecer objetivos y prioridades en cada materia o sector de acción pública, aproximándose mucho a los planes que según el art. 59 LRL habrá que formar para el ejercicio de las facultades de coordinación sobre las Corporaciones locales. Perfectamente podrán utilizarse también para 
El instrumento para alcanzar la coordinación resulta obligatorio para todas las Administraciones actuantes. Eso significa que en caso de conflicto entre la proyección territorial de los planes de actividad de cualquier Administración y las previsiones de los instrumentos autonómicos de ordenación del territorio, prevalecerán éstos, y aquéllos deberán ser modificados o retenidos. Sin embargo, cuando se trata de acciones de la Administración del Estado en el ejercicio de competencias exclusivas y se den los supuestos de urgencia y excepcional interés público, el conflicto lo resuelve el Consejo de Ministros ${ }^{60}$. De no ser así, la facultad de coordinación forzosa podrá ser ejercida por la Comunidad Autónoma también respecto del Estado.

\section{HACIA UN MODELO INTEGRADO DE COORDINACION}

\section{Introducción}

Como se habrá comprobado a través de las páginas precedentes, nuestro ordenamiento jurídico ofrece ya un sistema normativo bastante completo para regular la coordinación interadministrativa. Sin embargo, su grado de aplicación es todavía insuficiente, posiblemente a causa de la heterogeneidad de las técnicas de coordinación, su dispersión y -sobre todo- por la ausencia de modelos integrados que además gocen de amplio respaldo entre los agentes político-administrativo llamados a aplicarlos. Es por ello por lo que, antes de finalizar el presente estudio, nos ha parecido conveniente -casi obligatorio- formular las líneas generales de un modelo integrado, a pesar incluso de que seamos conscientes del riesgo que se corre con este tipo de tentativas. Sirve a este propósito también el describir los elementos de tal modelo integrado de coordinación recogidos en el

este fin, ya que - además - intentan limitarse a determinar un marco de actuación sin atentar a la propia autonomía local: art. 19 y 25 L. 7/1990 de Cantabria (planes directores sectoriales); art. 14 y 18 Ley 10/84 de Madrid (programas coordinados); art. 23 Ley $8 / 1987$ de Baleares (planes directores sectoriales); art. 4.10, 12 y 15 de la L. 6/1989 de Valencia (planes de acción territorial de carácter sectorial); art. 29 y 30 de la Ley 1/87, de Asturias (directrices sectoriales).

${ }^{60}$ Las directrices de ordenación del territorio resultan normalmente obligatorias para todas las Administraciones actuantes, para coordinar sus políticas sectoriales sobre el territorio y establecer mecanismos para resolver los conflictos que surjan: Asturias, Ley 1/87, art. 6.2.c. y 7 h.; País Vasco, Ley 4/1990, art. 8: o Baleares, L.8/1987, art. 13.1.b. En ocasiones el carácter vinculante de las directrices admite grados o modos de sujeción diferentes, pues a veces propondrán una fórmula obligatoria excluyente de cualquier otra, y otras veces abrirán la posibilidad de elegir entre dos o más modalidades de cumplimiento contenidas en las propias directrices, o se limitarán a dar pautas generales orientativas complementables por la Administración actuantes: art. 10 y 17 Ley 1/87 de Asturias. 
Acuerdo Autonómico de 1992, así como en la Ley Básica de Régimen de las Administraciones públicas.

El modelo que proponemos tiene carácter general, incluyendo a todas las Administraciones y para cualquier sector de actividad pública. Para su aplicación a cada materia se debería seguir, luego, un proceso de ajuste a cada una de ellas, conforme a una metodología muy similar a la siguiente:

a) Análisis del reparto de competencias de las diferentes Administraciones públicas en la materia, y determinación de en qué fase de la actuación administrativa en el concreto sector analizado (anteproyecto, plan o programa, ejecución, control, corrección de errores) aparece con más claridad la participación de las diferentes Administraciones.

b) Análisis y diagnóstico de los supuestos más frecuentes de descoordinación, sus causas y sus efectos, en la materia en cuestión.

c) Elaboración para cada materia (tal vez en las respectivas Conferencias Sectoriales) de un sistema integrado de coordinación que afecte a todas las Administraciones públicas.

d) Seguidamente, control e impulso del susodicho modelo.

A continuación pasamos a exponer ese modelo integrado general de coordinación; si bien abordaremos su explicación por separado (primero lo relativo a Corporaciones locales y luego a Comunidades Autónomas), es sólo para mejor corresponderse con la precedente sistemática, pero tiene el conjunto vocación de aplicación integrada.

\section{Coordinación de la actividad de las Corporaciones locales con la de otras Administraciones: un modelo integrado}

Nos hemos planteado la conveniencia de ofrecer un modelo de aplicación conjuntada y operativa de todo el sistema, que ordene consecutivamente y enlace debidamente la primera fase de actuación cooperativa voluntaria y la segunda de coordinación condicionada. Asimismo, pretendemos ofrecer una solución al problema de la armonización entre los diferentes planes o programas territoriales (de cada entidad con las demás), y entre éstos y los de naturaleza sectorial. A la exposición de este modelo dedicaremos las próximas páginas. 


\subsection{Un sistema integrado de coordinación sectorial}

La coordinación condicionada, no proveniente de la libre cooperación, se alcanza por la vía establecida en el artículo 59 de la Ley; a esta última fase del proceso coordinador nos hemos referido más atrás. Pero queremos recordar también aquí que legalmente se exige en tal supuesto la elaboración previa de un Plan sectorial donde se formulen los objetivos de la acción pública en la materia y se determinen las prioridades al abordar su consecución. Pues bien, este Plan debe de estar elaborado y aprobado previamente a que se produzcan los excepcionales supuestos de hecho que ponen en marcha este tipo de acción coordinadora, por lo que nos hemos planteado la conveniencia de que tal instrumento planificador pueda -además- cumplir también funciones coordinadoras en la fase previa de la libre cooperación. El sistema contará, pues, desde el principio, con unos objetivos y prioridades -a los que venimos denominando instrucciones generales para la coordinación sectorial - que determinarán la orientación básica de las acciones desarrolladas cooperativamente, e incluso de las emprendidas por una sola Administración aisladamente.

Una vez que se define, concretamente y en relación con una materia, servicio o competencia determinados, los intereses generales o comunitarios, el ámbito del Plan queda fijado. Llegado el caso, ese será el campo de juego de la coordinación forzosa, mediante la sujeción de la actividad local a las instrucciones generales para tal materia o sector establecidos por el Plan; pero - entretanto- la actividad local podrá guiarse por estos faros indicadores para libremente converger en los objetivos deseables. Cuestión importante, por cierto, resulta ahora el plantearnos cómo se pone en marcha el sistema antes de que las correspondientes Leyes sectoriales resulten aprobadas, en este período por cierto tan importante para someter la actividad del Estado a unas pautas de comportamiento acompasadas a las de los demás Estados miembros de la Comunidad Económica Europea. El problema es serio, porque el requisito formal de la Ley sectorial previa constituye una garantía frente a posibles abusos en nombre del principio de coordinación, y -en consecuencia- cualquier Corporación local puede resistirse legítimamente a que se le impongan condicionamientos a su acción si no se ha seguido el procedimiento legalmente establecido. Es claro que la coordinación forzosa no podrá funcionar hasta tanto no se den todos estos requisitos legales; sin embargo, pensamos que ello no debe constituir impedimento para que ya desde ahora se ponga en marcha el sistema que proponemos, y se redacten los Planes sectoriales de coordinación tal como enseguida explicaremos. 


\subsection{El Plan Sectorial de Cooperación}

En la elaboración del Plan Sectorial de Coordinación debe seguirse un procedimiento lo más participativo posible; precisamente el éxito del funcionamiento del sistema cooperativo que sobre él se montará está en que todos estén desde el principio en el negocio. Más arriba se propuso un modelo de participación en la programación, que aquí resulta válido. Debe entenderse que el titular de la facultad de aprobar el Plan es solamente el Gobierno de la Nación o el Consejo de Gobierno de la Comunidad Autónoma, según los casos; pero que previamente al acto final de aprobación formal se desarrollará un proceso de elaboración en el que las demás Administraciones públicas presenten en el territorio intervengan en las distintas fases del mismo.

El PSC podría contener los siguientes epígrafes o apartados:

A) Instrucciones Generales para la Coordinación.

B) Recomendaciones.

C) Directrices para el ejercicio de las competencias delegadas a las Administraciones locales.

D) Módulos de funcionamiento y financiación, y niveles de rendimiento mínimo en la gestión de servicios comunitarios encomendada a las Diputaciones provinciales o Cabildos insulares.

E) Oferta de Cooperación.

F) Condiciones y límites de la coordinación forzosa.

G) Relación de actividades de las diferentes Administraciones públicas.

H) Organización para la cooperación.

A continuación pasamos a describir cada uno de estos apartados:

\section{A) Instrucciones Generales para la Coordinación}

Señalada por la Ley sectorial la materia, servicio o competencia respecto de la cual se otorgan facultades de coordinación, procederá que el coordinador determine los intereses generales o comunitarios mediante el establecimiento de unos objetivos y prioridades, a los 
que hemos convenido en denominar Instrucciones Generales para la coordinación.

\section{B) Recomendaciones}

Todo el contenido orientador y directivo del Plan no está llamado a imponerse por la vía del artículo 59 LRBRL; caben otras determinaciones de naturaleza diferente a las Instrucciones Generales para la coordinación, también con capacidad orientadora, complementarias de las Instrucciones, pero sin la fuerza vinculante que aquéllas pueden llegar a alcanzar si falla todo el proceso previo de libre cooperación. De hecho, en toda la primera parte, que normalmente deberá ser la única, del proceso coordinador, las Instrucciones también jugarían como recomendaciones, adquiriendo sólo su carácter condicionante en el supuesto extremo y excepcional del artículo 59 de la Ley.

Deberá, pues, incluirse en el Plan un cuadro de recomendaciones dirigidas a la actividad de todas las Administraciones públicas sobre el territorio, ya sea que decidan en cada caso actuar cooperativamente, ya sea -incluso- que opten por ejercitar su competencia por sí solas. Estas recomendaciones son auténticos puentes tendidos a la actuación solidaria y leal, son seductoras invitaciones a la cooperación. Se puede resistir una imposición, pero resulta muy difícil rechazar siempre la recomendación para la actuación armónica. ¿Quién se atreve a colocarse siempre frente a la mayoría, a situarse siempre al margen de la sensatez y la racionalidad que representa la cooperación?

Poco más hay que decir acerca del contenido de las recomendaciones: podrán referirse a la forma en que las competencias propias deban ser ejercidas, o a los ritmos en su ejercicio, o a la determinación de objetivos y prioridades complementarias de los incluídos en las Instrucciones Generales para la coordinación. Precisamente su utilidad procede de su versatilidad y de su flexibilidad.

Finalmente, debemos señalar que la inclusión de recomendaciones en el PSC no debe detenerse con su aprobación inicial, pues a lo largo de su aplicación podrá recomendar la introducción de retoques o pequeñas modificaciones en los mismos, o la inclusión de recomendaciones nuevas. Lo único que debe de permanecer inalterable, para evitar inseguridad, pérdida de ritmo y cambios de orientación en las Administraciones locales, son las Instrucciones Generales; las recomendaciones, si 
bien se tenderá a lograr la mayor estabilidad posible, pueden ser modificadas o completadas sucesivamente.

C) Directrices para el ejercicio de las competencias delegadas a las Administraciones locales

El PSC debe ser el soporte de estas directrices, a las que se refiere el artículo 5 de la Ley del Proceso Autonómico, y más precisamente los artículos 27.2 y 37.1 LRBRL.

D) Módulos de funcionamiento y financiación, y niveles de rendimiento mínimo en la gestión de servicios comunitarios encomendada a las Diputaciones o Cabildos.

Puesto que la encomienda o encargo de gestión es también por materias o sectores, cabe perfectamente su ubicación en el Plan Sectorial, con lo que aumenta su capacidad informativa del conjunto de relaciones interadministrativas en la materia. Como es bien sabido esta técnica, regulada en el artículo 6 de la LPA, tampoco puede ir en perjuicio de los servicios de la entidad local.

\section{E) Oferta de Cooperación}

Aunque como hemos dicho todo el Plan constituye una invitación a la cooperación, sin embargo resultaría muy útil establecer un cuadro o esquema comprensivo de la oferta de cooperación que a todas las Administraciones públicas sobre el territorio se dirige. En él podrán incluirse concretos proyectos a desarrollar a través de algunas de las diversas modalidades de cooperación (que luego estudiaremos), incentivos económico-financieros para fomentar la convergencia, y los distintos instrumentos y procedimientos cooperativos que se decida utilizar. No se trata de una relación de lo ya convenido para la cooperación, sino un planteamiento de las opciones de cooperación - "a la cartan- que se ofrecen, señalando las técnicas y modalidades que para cada caso más convenga elegir.

\section{F) Condiciones y límites de la coordinación}

La propia Ley sectorial, a tenor de lo dispuesto por el artículo 59.2, debería precisar, con el suficiente grado de detalle, las condiciones y límites de la coordinación, así como las modalidades sobre el modo de ejercicio de la facultad de coordinación. 


\section{G) Relación de actividades de las diferentes Administraciones}

Igualmente se incluirá en el Plan un listado de las actividades programadas por las distintas entidades públicas sobre el territorio. Se pretende con ello ofrecer un panorama general de toda la actuación pública en la materia, con independencia de la forma en que se ejecute, e incluyendo por tanto también la actividad local a realizar por una Corporación pública fuera de todo programa de cooperación. Se trata, pues, de reflejar toda la actividad pública en un único documento, ya que esto permite detectar duplicidades y contradicciones, ayudando a su vez a la coordinación general en el sector.

Se anotarían en esta relación los programas y proyectos ya decididos, con descripción de las obras o servicios que comporte, así como referencia a la previsión de fecha de finalización, modalidades de ejecución y determinación del modo de financiación. La inclusión de un programa o un proyecto en ningún caso supone un compromiso de la Administración o Administraciones que se proponen desarrollarla, pues su finalidad es meramente informativa y para facilitar la coordinación. Por otro lado, se trata de una relación abierta, que aunque tiene vocación de incluirlo todo desde un principio, no queda cerrada a la aceptación de nuevas anotaciones.

\section{Coordinación de Comunidades Autónomas y Estado: un mo- delo integrado}

También aquí el sistema debe basarse en planes sectoriales, a los que denominaremos — con la terminología de la Ley General de SanidadPlanes Integrales.

El Plan Integral sería aprobado por el Gobierno de la Nación; pero a lo largo del proceso de su elaboración participarían activamente las diferentes Administraciones (especialmente las Comunidades Autónomas, pues las Corporaciones locales de hecho sólo podrían hacerlo a través de su Federación nacional).

Dos tipos bien diferenciados de Planes Integrales: aquellos correspondientes a materias respecto de las cuales el Estado ostenta competencia coordinadora (149.1.CE), y aquellos otros en que la competencia sectorial del Estado es compartida o concurrente respecto de la de las Comunidades Autónomas; en los demás supuestos, donde el Estado carece ć. Ciñ petencia alguna, no cabrá intentar por su parte acciones de coordinación, salvo que éstas sean solicitadas expresamente por todas las Comunidades Autónomas en atención a su necesidad (por ejemplo 
REALA 255-256 (JULIO-DICIEMBRE, 1992)

a partir de Conferencias Sectoriales en las que los participantes convengan en establecer un sistema coordinado para todo el territorio nacional).

En el primer caso, el Plan Integrado contendrá una parte obligatoria para Comunidades Autónomas (149.1 CE) y Corporaciones locales (59 LRL), consistente en objetivos y prioridades; aquí también cabrá relacionar los Convenios de Conferencia Sectorial o de Cooperación suscritos en la materia, que también tienen carácter obligatorio. El Plan Integrado podrá, además, incorporar un conjunto de instrumentos de programación similar al que proponíamos más atrás para los PSC (apartado 2.2 de este mismo capítulo).

En el segundo caso, cuando el Estado sólo ostenta competencias compartidas pero no la exclusiva de coordinar, podrá así y todo incluirse un contenido obligatorio (directrices: objetivos y prioridades) para vincular a las Corporaciones locales (59 LRL). Por lo demás, su contenido se completará de igual forma que en el apartado anterior, pudiendo incluir además planes conjuntos, acciones comunes y proyectos cofinanciados. 